\title{
Conformation and aggregation of selectively PEGylated and lipidated gastric peptide hormone human PYY3-36
}

Article

Accepted Version

Castelletto, V., Hamley, I. W., Seitsonen, J., Ruokolainen, J., Harris, G., Bellmann-Sickert, K. and Beck-Sickinger, A. G. (2018) Conformation and aggregation of selectively PEGylated and lipidated gastric peptide hormone human PYY3-36.

Biomacromolecules, 19 (11). pp. 4320-4332. ISSN 1525-7797 doi: https://doi.org/10.1021/acs.biomac.8b01209 Available at https://centaur.reading.ac.uk/79850/

It is advisable to refer to the publisher's version if you intend to cite from the work. See Guidance on citing.

To link to this article DOI: http://dx.doi.org/10.1021/acs.biomac.8b01209

Publisher: American Chemical Society

All outputs in CentAUR are protected by Intellectual Property Rights law, including copyright law. Copyright and IPR is retained by the creators or other copyright holders. Terms and conditions for use of this material are defined in the End User Agreement. 


\section{CentAUR}

Central Archive at the University of Reading

Reading's research outputs online 


\title{
Conformation and Aggregation of Selectively PEGylated and Lipidated Gastric Peptide Hormone Human PYY3-36
}

\author{
Valeria Castelletto, ${ }^{*}$ Ian W Hamley,* \\ Department of Chemistry, University of Reading. Whiteknights, Reading RG6 6AD, \\ United Kingdom
}

Jani Seitsonen, Janne Ruokolainen,

Department of Applied Physics, Aalto University School of Science, P.O. Box 15100 FI-00076 Aalto, Finland

Gemma Harris,

Diamond Light Source Ltd. Harwell Science and Innovation Campus, Fermi Ave, Didcot OX11 ODE, United Kingdom

Kathrin Bellmann-Sickert, and Annette G. Beck-Sickinger

Institute of Biochemistry, Faculty of Life Science, Leipzig University, Brüderstrasse 3, D 04103 Leipzig, Germany

* Authors for Correspondence 


\section{Abstract}

The gastric peptide hormone human $\mathrm{PYY}_{3-36}$ is a target for the development of therapeutics, especially for treatment of obesity. The conformation and aggregation behaviour of PEGylated and lipidated derivatives of this peptide is examined using a combination of fluorescence dye assays, circular dichroism (CD) spectroscopy, analytical ultracentrifugation (AUC) measurements, small-angle x-ray scattering (SAXS) and cryogenic-transmission electron microscopy (cryo-TEM). The behaviour

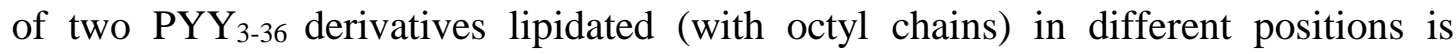
compared to that of two derivatives with PEG attached at different residues and to that of the native peptide. We find that, unexpectedly, PYY $3-36$ forms amyloid fibril structures above a critical aggregation concentration. Formation of these structures is suppressed by PEGylation or lipidation. PEGylation significantly reduces the

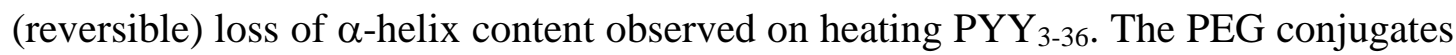
form mainly monomeric structures in solution, coiled coil formation and other aggregation presumably being sterically hindered by swollen PEG chains. However, some small aggregates are detected by AUC. In complete contrast, both of the two lipidated peptides show the formation of spherical micelle-like structures which are small oligomeric aggregates. Our findings show that PEGylation and lipidation are complementary strategies to tune the conformation and aggregation of the important gastric peptide hormone human $\mathrm{PYY}_{3-36}$. 


\section{Introduction}

Obesity is fast emerging as a global healthcare issue and this has stimulated research to understand the condition and ultimately to develop treatments. A key area of interest concerns peptide hormones, a series of which are involved in appetite stimulation or suppression. ${ }^{1}$ These peptide hormones are secreted from organs including the pancreas, stomach and intestine.

The Neuropeptide Y (NPY) family of peptide hormones are secreted in the gut and are involved in several processes involved with the feeling of satiety following feeding. ${ }^{2}$ These neuropeptides serve as ligands for G-protein coupled Y receptors. The NPY family includes peptide YY (PYY), NPY and pancreatic peptide (PP). ${ }^{3-4}$ Here, we investigate derivatives of the human $\mathrm{PYY}_{3-36}$ peptide. This peptide is a gut hormone released by the L cells of the gastrointestinal tract following food intake and it is produced from the endogenous precursor $\mathrm{PYY}_{1-36}$ peptide via rapid hydrolysis to the 34 amino acid peptide, PYY $3-36$, by the peptidase enzyme DPP4 which removes the first two amino acids, tyrosine and proline, at the N-terminus. ${ }^{5}$ This alters the receptor selectivity and as a result $\mathrm{PYY}_{3-36}$ has a high selectivity for the $\mathrm{Y}_{2}$ receptor, compared to $P Y Y_{1-36}$ which has selectivity for the $\mathrm{Y}_{1}, \mathrm{Y}_{2}$, and $\mathrm{Y}_{5}$ receptors. ${ }^{6}$ The sequence of PYY $_{3-36}$ is shown in Scheme 1a which also shows the lipidated and PEGylated derivatives studied in this paper. Solution NMR studies have established that PYY adopts a partially $\alpha$-helical structure in aqueous solution. ${ }^{7-8}$ Residues from $L(17)$ to $\mathrm{T}(32)$ are believed to lie in the $\alpha$-helical domain as shown in red in Scheme 1b. The helical wheel representation of the alpha helix of PYY $\mathrm{PY}_{36}$ (Scheme 1c) suggests a possible tendency for facial segregation of charged residues (bottom right) and uncharged residues (top left). 
In the present manuscript, we investigate the effect of PEGylation and lipidation on the conformation and aggregation of derivatives of PYY. The conformation is probed using circular dichroism (CD) spectroscopy. This technique also provides some information on aggregation, however this is examined with less ambiguity via analytical ultracentrifugation. Potential self-assembly is investigated using a powerful combination of cryogenic-transmission electron microscopy (cryo-TEM) and in situ small-angle X-ray scattering (SAXS). PEGylation of PYY 3 -36 leads to extended circulation half-life, although its activity in inhibiting food intake was found to be eliminated (in a mouse model). ${ }^{9}$ However, attachment of PEG via a hydrolysable linker restored this activity. ${ }^{9}$ In another study, palmitoylated $\mathrm{PYY}_{3-36}$ derivatives were reported to show self-assembly behaviour (into nanotape or micellar structures depending on $\mathrm{pH}) .{ }^{10}$ Here, we show that the octyl lipid derivatization suppresses the fibrillisation observed for $\mathrm{PYY}_{3-36}$ itself and instead stabilizes the formation of micelles. We also demonstrate that PEGylation leads to the formation of PEG-stabilized monomers, i.e. the PEG is shown to have a valuable role in preventing self-assembly. This paper complements a recent manuscript on the conformation and self-assembly of several PYY peptides substituted with lysine bearing $\gamma$-glutamyl linked palmitoyl lipid chains at $\mathrm{S}(13), \mathrm{R}(19)$ or $\mathrm{R}(25) .{ }^{10}$ In the current paper, lipidation involves substitution of $\mathrm{L}(17)$ or $\mathrm{Y}(21)$ with octyl-bearing lysine derivatives or substitution of lysine derivatives bearing short PEG oligomers. Both of these sites have been chosen to lie within the $\alpha$-helical domain (Scheme 1b). Based on a complete alanine scan of neuropeptide Y, a close homologue of PYY activating the same receptors, binding to the human $\mathrm{Y}_{2}$ receptor (a receptor for pancreatic peptide hormones) only depends on residue 5 and final C-terminus sequence. Hence, positions 17 and 21 were chosen as they lie in the centre of the molecule at one face of the alpha-helix and can freely be 
substituted and modified without obstructing the peptide activity at the human $\mathrm{Y}_{2}$ receptor. ${ }^{11}$ The conformation of $\mathrm{PYY}_{3-36}$ has been determined from solution NMR studies. Scheme 2a shows an ensemble of conformers obtained from one of these studies (published as pdb file $2 \mathrm{dez}){ }^{12}$

There have been few other prior studies on PYY peptide derivatives. One investigation of conjugation of Vitamin B21 to $\mathrm{PYY}_{3-36}$ which has been shown to lead to improved function, in particular reduced food intake in a rat model. ${ }^{13}$ An NMR-based structure of the conjugate, used as a constraint in molecular dynamics simulation modelling, was also published. ${ }^{14}$

Improving the chemical and physical stability of peptides for applications as therapeutic agents is an important research challenge. ${ }^{15-16}$ Strategies include conjugation of lipid and polymer chains. A commonly used polymer for such applications is polyethylene glycol (PEG), attachment of which is termed PEGylation. PEGylation is a well-known strategy to improve the stability of proteins and peptides in vivo, ${ }^{17-23}$ as a result of socalled steric stabilization, and this action was confirmed for a human PP (hPP) derivative (PEGylated at lysine residue 22). ${ }^{24}$ This was also shown to reduce food intake in mice. ${ }^{24}$ It has been shown that PEGylation (N-terminal or $\mathrm{N}$ - and C-terminal) stabilizes the conformation of de novo designed coiled coil forming peptides against changes in concentration and temperature. ${ }^{25-26}$

Lipidation is another strategy employed to improve the biostability of peptides for therapeutic applications and it enhances compatibility of the molecule with lipid membranes and facilitates extended circulation via binding to serum albumin. ${ }^{27-29}$ In 
one study on a lipidated NPY family peptide, Bellman-Sickert et al. showed that lipidation improved the pharmacokinetic properties of hPP and prolonged the reduction of food consumption in a mouse model. ${ }^{29}$ The lipidated peptide showed a greater resistance to degradation and excretion than PEG analogues which were also prepared and investigated.

\section{Experimental}

Synthesis. Peptides were synthesized as described previously. ${ }^{30}$ Briefly, peptide sequences were built up using solid phase peptide synthesis on a Rink amide resin. For PEGylation, N-termini as well as Lys side chains that were not intended to be PEGylated were blocked by the UV-cleavable 6-nitroveratryloxycarbonyl (Nvoc) protection group. Peptides were cleaved from the resin and reacted in solution with MeO-PEG-NHS with an average molecular weight of $22 \mathrm{kDa}$ in the presence of 4dimethylaminopyridine in DMF. Afterwards, the Nvoc protection group was cleaved. For lipidation, Lys side chains were protected using the N-(1-(4,4-dimethyl-2,6dioxocyclohexylidene)ethyl) (Dde) group. The N-terminus was tert-butyloxycarbonyl (Boc) protected. After selective deprotection of Lys with hydrazine, the $\gamma$-L-glutamoyl linker was introduced the following way: Fmoc-L-Glu-OtBu was coupled via the $\gamma$ carboxy group of the glutamoyl side chain using carboxyacid activation with $\mathrm{N}, \mathrm{N}-$ diisopropylcarbodiamide (DIC) and hydroxybenzotriazole (HOBT), followed by cleavage of fluorenylmethoxycarbonyl (Fmoc) and coupling of octanoic acid using the same activation technique. After cleavage from the resin, all peptides were purified by reversed phase high performance liquid chromatography. Identity was proven by matrix assisted laser desorption/ionization time of flight mass spectrometry. The attached PEG 
has a molar mass of 22271 Da (MeO-PEG-NHS 20000 Da from Iris Biotech GmbH) and a dispersity $\mathrm{D}=1.04$. Molecular weights were $4047.07 \mathrm{~g} / \mathrm{mol}\left(\mathrm{PYY}_{3-36}\right), 4317.23$ $\mathrm{g} / \mathrm{mol}$ (K 17 -Eoct), $4267.25 \mathrm{~g} / \mathrm{mol}$ (K $\mathrm{K}_{21}$-Eoct), 24,000 g/mol ( $\left.\mathrm{K}_{17}-\mathrm{PEG}_{22}\right)$ and 26267 $\mathrm{g} / \mathrm{mol}\left(\mathrm{K}_{21}-\mathrm{PEG}_{22}\right)$ determined by mass spectrometry using an Ultraflex III MaldiTOF/TOF (Bruker Daltonics, Bremen, Germany).

Sample Preparation. For circular dichroism (CD), cryo-transmission microscopy (cryo-TEM), small angle X-ray scattering (SAXS) and automatic ultracentrifugation (AUC) studies, weighed amounts of peptide powder and water were left to equilibrate at the desired wt $\%$ concentration of peptide. For ANS and ThT assays, the peptides were dissolved in a stock solution containing the corresponding fluorophore.

Fluorescence Spectroscopy. 8-anilo-1-naphthalenesulfonic acid (ANS) and Thioflavin T (ThT) were used to locate the critical aggregation concentration (cac). The ANS fluorophore is sensitive to the hydrophobicity of its surrounding environment, ${ }^{31}$ making it suitable to determine the cac due to hydrophobic collapse. ThT fluorescence binds to amyloid-like structures ${ }^{32-33}$ ( $\beta$-sheet fibrils) and is used to detect the $c a c$ due to amyloid formation. Samples for ANS or ThT assays were prepared by dilution in $2 \times 10^{-}$ ${ }^{3} \mathrm{wt} \%$ ANS or $5 \times 10^{-3} \mathrm{wt} \%$ ThT of a mother sample prepared as $0.2 \mathrm{wt} \%$ peptide in $2 \times 10^{-3} \mathrm{wt} \%$ ANS or $5 \times 10^{-3} \mathrm{wt} \%$ ThT.

Spectra were recorded with a Varian Cary Eclipse Fluorescence Spectrometer with samples in $4 \mathrm{~mm}$ inner width Quartz cuvettes.

ANS assays were performed measuring spectra from 400 to $670 \mathrm{~nm}\left(\lambda_{\mathrm{ex}}=356 \mathrm{~nm}\right)$, while ThT assays were performed measuring spectra from 460 to $600 \mathrm{~nm}\left(\lambda_{\mathrm{ex}}=440\right.$ $\mathrm{nm})$.

Results from the ANS or ThT assays are plotted as $I / I_{0} v s c$ or $v s \log (c)$ (I: fluorescence intensity of peptide dissolved in $2 \times 10^{-3}$ wt $\%$ ANS or $5 \times 10^{-3} \mathrm{wt} \%$ ThT; $I_{0}$ : fluorescence 
intensity of $2 \times 10^{-3} \mathrm{wt} \%$ ANS or $5 \times 10^{-3} \mathrm{wt} \%$ ThT; $\lambda_{\text {em }}$ : emission wavelength, $c$ : peptide concentration).

Analytical Ultracentrifugation (AUC). For characterisation of the peptide solutions, sedimentation velocity scans were recorded for a dilution series, starting from $0.1 \mathrm{wt} \%$ conjugated peptide. All experiments were performed at $55000 \mathrm{rpm}$, using a Beckman XLI analytical ultracentrifuge with an An-60Ti rotor at $20^{\circ} \mathrm{C}$. Data were recorded using the absorbance (at $280 \mathrm{~nm}$ ) and interference optical detection systems. The density and viscosity of the water was measured experimentally using a DMA 5000M densitometer equipped with a Lovis 200ME viscometer module. The partial specific volume of the peptide was calculated using SEDFIT from the amino acid sequence. The partial specific volume of PEG was taken as $0.825 \mathrm{~mL} / \mathrm{g},{ }^{34}$ and that of the lipid was calculated using the method of Durchschlag and Zipper. ${ }^{35}$

The theoretical apparent partial specific volumes $\left(\bar{v}_{T}\right)$ of the conjugated peptides were calculated according to:

$$
\bar{v}_{T}=\frac{\left(M_{P} \bar{v}_{P}\right)+\left(M_{C} \bar{v}_{C}\right)}{\left(M_{P}+M_{C}\right)}
$$

Where $M_{P}$ and $\bar{v}_{P}$ denote the molecular mass and partial specific volume of the peptide, respectively, and $M_{C}$ and $\bar{v}_{C}$ denote the molecular mass and partial specific volume of the conjugate, respectively. Data were processed using SEDFIT, fitting to the $c(s)$ model. ${ }^{36}$

Circular Dichroism (CD) Spectroscopy. CD spectra were recorded using a Chirascan spectropolarimeter (Applied Photophysics, UK). Peptide solutions were placed in a quartz bottle (1 mm path length). Spectra were measured with a $0.5 \mathrm{~nm}$ step, $1 \mathrm{~nm}$ bandwidth, and $1 \mathrm{~s}$ collection time per step. The CD signal from the water background was subtracted from the $\mathrm{CD}$ data of the sample solutions. Temperature was manually 
changed, while the sample was left to equilibrate for 3 minutes after the assigned temperature has been reached, before collecting the $\mathrm{CD}$ data.

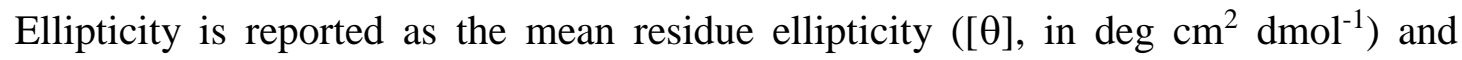
calculated as:

$$
[\theta]=[\theta]_{o b s} \frac{\mathrm{MRW}}{10 c l}
$$

$[\theta]_{o b s}$ is the ellipticity measured in millidegrees, MRW is the mean residue molecular weight of the peptide (molecular weight divided by the number of amino acid residues $=34$, Scheme 1), $c$ is the total concentration in $\mathrm{mg} / \mathrm{ml}$, and $l$ is the optical path length of the cell in centimeters.

CD spectra were dominated by an $\alpha$-helical secondary structure. The $\alpha$-helix content, $f_{\alpha}$, is calculated as: $:^{37}$

$$
f_{\alpha}=100[\theta]_{222} /[\theta]_{222}^{e x}
$$

$[\theta]_{222}^{e x}$ in Equation 3 is the extrapolated value for the molar ellipticity:

$$
[\theta]_{222}^{e x}=[\theta]^{\infty}\left(1-\frac{k}{n}\right)
$$

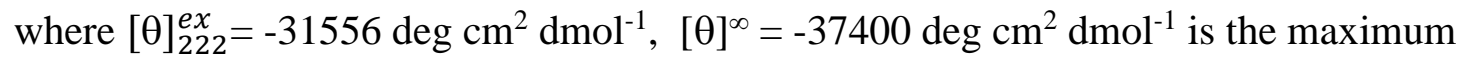
mean residue ellipticity at $222 \mathrm{~nm}$ of a peptide with infinite length and $100 \%$ helix content, ${ }^{37} n=16$ is the number of residues/helix (Scheme $1 \mathrm{~b}$ ) and $k$ is a wavelengthdependent constant (2.5 at $222 \mathrm{~nm})$.

Cryogenic-Transmission Electron Microscopy (Cryo-TEM). Imaging was carried out using a field emission cryo-electron microscope (JEOL JEM-3200FSC), operating at $200 \mathrm{kV}$. Images were taken in bright field mode and using zero loss energy filtering (omega type) with a slit width of $20 \mathrm{eV}$. Micrographs were recorded using a Gatan Ultrascan 4000 CCD camera. The specimen temperature was maintained at $-187{ }^{\circ} \mathrm{C}$ during the imaging. Vitrified specimens were prepared using an automated FEI 
Vitrobot device using Quantifoil 3.5/1 holey carbon copper grids with a hole size of 3.5 $\mu \mathrm{m}$. Just prior to use, grids were plasma cleaned using a Gatan Solarus 9500 plasma cleaner and then transferred into the environmental chamber of a FEI Vitrobot at room temperature and $100 \%$ humidity. Thereafter $3 \mathrm{ml}$ of sample solution was applied on the grid and it was blotted twice for 5 seconds and then vitrified in a 1/1 mixture of liquid ethane and propane at temperature of $-180{ }^{\circ} \mathrm{C}$. The grids with vitrified sample solution were maintained at liquid nitrogen temperature and then cryo-transferred to the microscope.

Small-Angle and X-Ray Scattering (SAXS). Synchrotron SAXS experiments on solutions were performed on beamline B21 at Diamond (Didcot, UK) and on ID02 (ESRF, France).

At B21, solutions were loaded into the 96 well plate of an EMBL BioSAXS robot, and then injected via an automated sample exchanger into a quartz capillary $(1.8 \mathrm{~mm}$ internal diameter) in the X-ray beam. The quartz capillary was enclosed in a vacuum chamber, in order to avoid parasitic scattering. After the sample was injected in the capillary and reached the X-ray beam, the flow was stopped during the SAXS data acquisition. B21 operated with a fixed camera length (3.9 m) and fixed energy (12.4 $\mathrm{keV})$. The images were captured using a PILATUS 2M detector. Data processing was performed using dedicated beamline software Scatter.

At ID02, samples were loaded in a glass capillary with a $2 \mathrm{~mm}$ internal radius. The beamline operated at $12.46 \mathrm{keV}$ energy with a flux of $2.19 \times 10^{12}$ photon s$^{-1}(100 \mathrm{~mA})$. The sample-detector distance was $1474.2 \mathrm{~mm}$. The 2D data was collected using a Rayonix MX170 ${ }^{38}$ detector, with a $2 \times 2$ binning, and processed using SAXSUtilities software. 


\section{Results}

We investigated the conformation and aggregation of $\mathrm{PYY}_{3-36}$ and derivatives of $\mathrm{PYY}_{3-}$ 36 shown in Scheme 1. We first used the software PEPfold $3^{39-40}$ to compute the predicted conformation of $\mathrm{PYY}_{3-36}$ in comparison to a published solution NMR structure. ${ }^{12}$ PEPfold3 provides de novo conformational analysis based on a structural alphabet analysis which considers a peptide in sequence of four residues overlapping by three residues and compares the conformation with sequences generated by positionspecific iterative BLAST analysis using Uniprot protein database, followed by

sterically allowed generation of progressively extended peptide conformations. ${ }^{39-40}$ Scheme $2 b$ shows an overlay of a PEPfold 3 predicted structure with one of the ensemble of NMR conformers. There is a good degree of conformity in predicted and experimental structures, although the predicted $\alpha$-helical domain is shifted slightly from the NMR conformation (and is slightly longer). This is also confirmed by the local conformational analysis shown in Scheme 2c, which shows a predominance of $\alpha$ helical structure from $\mathrm{S}(13)$ to $\mathrm{L}(30)$ (due to the structural alphabet overlap analysis, the conformation of the last two residues is not computed). For comparison, the software PSIPRED, based on the position specific scoring matrices generated by PSIBLAST, predicts that residues from $\mathrm{P}(14)$ to $\mathrm{V}(31)$ are in $\alpha$-helical conformation. ${ }^{41-42}$ This combination of experimental and theoretical evidence indicates that substitutions at $\mathrm{L}(17)$ or $\mathrm{Y}(21)$ in $\mathrm{PYY}_{3-36}$ correspond to substitutions in the $\mathrm{N}$-terminal region of the $\alpha$-helical domain or its centre. We then proceed to investigate the conformation and aggregation tendencies of $\mathrm{K}(17)$ and $\mathrm{K}(21)$ derivatives bearing octyl lipids or short PEG chains. These molecules have been prepared to enhance the biostability of PYY $3-36$ with possible therapeutic applications as discussed above. ${ }^{10}$ 
We compare the conformational behaviour and self-assembly properties of derivatives of PYY which have been PEGylated by attachment of PEG [poly(ethylene glycol)] at $\mathrm{K} 17$ or $\mathrm{K} 21\left(\mathrm{~K}_{17}-\mathrm{PEG}_{22}, \mathrm{~K}_{21}-\mathrm{PEG}_{22}\right.$; Scheme 1a) or lipidated via attachment of an octyl chain at K17 or K21 (K17-Eoct, $\mathrm{K}_{21}$-Eoct; Scheme 1a).

The self-assembly of $\mathrm{PYY}_{3-36}$ in water has recently been investigated. ${ }^{10}$ Here, results on the self-assembly of $\mathrm{PYY}_{3-36}$ in water (Figure 1) will be used as a reference for the PYY $3-36$ conjugates.

We first used a fluorescence dye probe to detect any critical concentration for aggregation or formation of hydrophobic pockets. The fluorescence of the dye ANS can be used to detect the $c a c$ as exemplified by our recent use of this method to detect $c a c$ values for several lipopeptides. ${ }^{43-44}$ ANS fluorescence assays are also frequently used to determine the formation of hydrophobic pockets during protein folding. ${ }^{31}$

Figure $\mathrm{S} 1$ shows the dependence of $I / I_{o}$ as a function of $\log (c)$, together with the dependence of the same normalized intensity on $c$ (inset Figure S1), measured for $\mathrm{PYY}_{3-36}$. The discontinuity in $I / I_{o}$ observed in the $\log (c)$ plot (Figure S1) is when the data is plotted on a linear concentration scale (inset Figure S1). Therefore, the ANS fluorescence assay does not show evidence for a self-assembly process driven by hydrophobic aggregation.

An alternative fluorescence assay, which uses ThT and is sensitive to the formation of amyloid fibrils, was used to determine the $c a c$ of $\mathrm{PYY}_{3-36}$. Figure 1a displays the results obtained from the ThT assay. A cac value $\sim 0.09 \mathrm{wt} \% \mathrm{PYY}_{3-36}$ can be obtained from the discontinuity in fluorescence intensity. This discontinuity is visible in the dependence of $I / I_{o}$ with $c$ (inset Figure 1a) or with $\log (c)$ (Figure 1a). This suggests that PYY 3-36 forms amyloid structures above a critical concentration. 
Cryo-TEM images reveal the self-assembly of long fibres (44.3 \pm 5$) \AA$ in diameter in a solution containing $1 \mathrm{wt} \% \mathrm{PYY}_{3-36}$. It has been reported that the self-assembly $\mathrm{PYY}_{3-}$ ${ }_{36}$ depends on the $\mathrm{pH}$ of the solution for $2 \leq \mathrm{pH} \leq 8 .{ }^{10}$ Here, $1 \mathrm{wt} \% \mathrm{PYY}_{3-36}$ in water has $\mathrm{pH} 3$, and fibres similar to those displayed in Figure $1 \mathrm{~b}$ were previously found for 0.5 wt\% $\mathrm{PYY}_{3-36}$ at $\mathrm{pH} 2$ and $4 .^{10}$

Since the fibril formation leads to a ThT fluorescence response, characteristic of amyloids we also investigated UV absorbance of the Congo red dye which is another diagnostic of amyloid formation. ${ }^{45}$ The expected green shift of the absorbance maximum was not observed. In fact, this phenomenon was observed previously for an $\alpha$-helical peptide (apolipoprotein A-I fragments) forming fibrils (as shown by TEM) ${ }^{46}$ Along with our results, this suggests that fibril-forming $\alpha$-helical peptides do not show all of the typical amyloid diagnostics, which is not surprising since the mode of binding of fluorescent dyes to $\alpha$-helical structures will differ from that of $\beta$-sheet structures, for which binding occurs in the grooves of the $\beta$-sheet fibrils. ${ }^{47-49}$

CD was used to study the secondary structure of the fibres in Figure $1 \mathrm{~b}$. The CD spectrum (Figure S2) displays two minima (208 and $219 \mathrm{~nm}$ ) and one maxima (189 $\mathrm{nm})$, corresponding to an $\alpha$-helical secondary structure. ${ }^{50}$ Equations 3-4 together with the spectrum in Figure $\mathrm{S} 2$ were used to calculate $f_{\alpha}=20 \%$ and the ratio $[\theta]_{222} /[\theta]_{208}=$ 0.9 , which might indicate that the fibres are not made of coiled-coil aggregates of $\alpha$ helices. $^{25,37}$

Figure 1c shows the CD signal for samples containing $8.6 \times 10^{-3}$ to $0.24 \mathrm{wt} \% \mathrm{PYY}_{3-36}$, which ranges across the $c a c$ determined by ThT fluorescence assays (Figure 1a). The relative intensity as well as the absolute value of the ellipticity at $\lambda=208$ and $222 \mathrm{~nm}$ changes with concentration, implying structural changes in the $\alpha$-helix conformation and coiled coil association. CD spectra in Figure 1c were used to calculate the helix 
contents $\left(f_{\alpha}\right.$; Equations 3-4) and the ratio of mean residual ellipticities at 222 and 208 $\mathrm{nm}\left([\theta]_{222} /[\theta]_{208}\right)$, which is a probe for the presence of coiled coil structures. ${ }^{37}$

Figure $1 \mathrm{~d}$ displays the results calculated for $f_{\alpha}$ and $[\theta]_{222} /[\theta]_{208}$ as a function of $\mathrm{PYY}_{3-}$ 36 concentration.

The analysis of the CD spectra provides low values of helical content $\left(18 \leq f_{\alpha} \leq 14\right.$, Figure 1d) because the $\alpha$-helices comprise only 16 residues out of the total 34 residues in the peptide sequence (Scheme $1 \mathrm{~b}$ ). It has been reported that values $[\theta]_{222} /[\theta]_{208} \sim 1$ or higher indicate the formation of coiled coil aggregates of $\alpha$-helices. ${ }^{25,37}$

A steady decrease of $[\theta]_{222} /[\theta]_{208}$ from $1.02-1.07$ to $0.87-0.93$, has been previously reported for synthetic peptides, and ascribed to the transition from two-stranded $\alpha$ helical coiled coils to single-stranded $\alpha$-helices. ${ }^{37,51-54}$

Figure 1d shows that upon increasing concentration, $[\theta]_{222} /[\theta]_{208}$ decreases from $\sim 1.1$ to $\sim 0.95$ above $0.05 \mathrm{wt} \% \mathrm{PYY}_{3-36}$. This suggests that coiled coils are present at low concentration, but that these are disrupted above the cac (where $[\theta]_{222} /[\theta]_{208}$ adopts a constant value $\sim 0.95$ ). The coiled coils present at low concentration are likely to be dimers when considering the likely pairwise facial aggregation (Scheme 1c). The loss of coiled coil structure at the cac is associated with the observation of fibrillar structures in the cryo-TEM image. However, the CD shows that the conformation is still $\alpha$-helical, i.e. these fibrils are formed by aggregation of helical PYY $3-36$ monomers. The observation of fibrils by a-helical peptides is rare (typically fibrils are associated with $\beta$-sheet assembly). It is possible to design $\alpha$-helices to form fibrils by incorporating "sticky ends", 55 in particular sequences with oppositely charged termini. Actually, inspection of the full $\mathrm{PYY}_{3-36}$ sequence (Scheme 1) shows a preponderance of $\mathrm{E}$ and $\mathrm{D}$ residues at the $\mathrm{N}$ terminus and several $\mathrm{R}$ residues near the $\mathrm{C}$ terminus so this is a 
possible origin of sticky ended coil aggregation into fibrils. It is notable that this requires consideration of the full peptide sequence and not just the core helical domain (Scheme 1c) in which there is no obvious pattern of charged residues.

The $\mathrm{PYY}_{3-36} \alpha$-helical structure steadily unfolds upon heating the sample from 10 to $80^{\circ} \mathrm{C}$ (Figure 1e). The smooth decrease of $f_{\alpha}$ with increasing $\mathrm{T}$ (inset Figure 1e) reveals a cooperative unfolding. This structural change is also reversible, since $\mathrm{PYY}_{3-36}$ folds back to its original structure when the temperature is decreased from 80 to $20^{\circ} \mathrm{C}$ (Figure 1f).

Having discussed the conformation and self-assembly of PYY $3-36$ itself, we compared it with the conformational behaviour and self-assembly of $\mathrm{K}_{17}-\mathrm{PEG}_{22}, \mathrm{~K}_{21}-\mathrm{PEG}_{22}, \mathrm{~K}_{17-}$ Eoct and $\mathrm{K}_{21}$-Eoct (Scheme 1a).

ANS emission fluorescence spectra for solutions containing $\mathrm{K}_{17}$-Eoct, $\mathrm{K}_{21}$-Eoct, $\mathrm{K}_{17}$ $\mathrm{PEG}_{22}$ and $\mathrm{K}_{21}-\mathrm{PEG}_{22}$ were characterized by a single maximum, which showed a simultaneous blue shift and intensity enhancement upon increasing concentration of peptide. A representative example is displayed in Figure $\mathrm{S} 3$ for $\mathrm{K}_{17}$-Eoct. Plots of $I / I_{o}$ $v s c$ for the peptide conjugates are displayed in Figure S4.

The ANS fluorescence blue shift and intensity enhancement results from ion pair formation between the sulfonate group of ANS and the charged group of Arg residues, when the probe is hosted in a non-polar environment. ${ }^{31,43,56-59}$ Here, the Arg residues are in the $\alpha$-helix region and the C-termini of the $\mathrm{PYY}_{3-36}$ backbone (Scheme $1 \mathrm{~b}$ ). ${ }^{10}$ As a consequence, higher values of $I / I_{o}$ are due to stronger binding between ANS and the Arg groups in a non-polar environment. This effect can explain the trend displayed in Figures $\mathrm{S} 4$ and $\mathrm{S} 1: I / I_{o}\left(\mathrm{~K}_{21}-\mathrm{EOct}\right)>I / I_{o}\left(\mathrm{~K}_{17}-\mathrm{EOct}\right)>I / I_{o}\left(\mathrm{~K}_{21}-\mathrm{PEG}_{22}\right)>I / I_{o} \mathrm{~K}_{17-}$ $\left.\mathrm{PEG}_{22}\right)$, all values also being higher than $I / I_{o}\left(\mathrm{PYY}_{3-36}\right)$. Clearly, lipidation or PEGylation of PYY $\mathrm{PY}_{36}$ influences the binding affinity of ANS. 
While $I / I_{o}$ vs $c$ can be fitted with a straight line for $\mathrm{K}_{17}-\mathrm{PEG}_{22}$ and $\mathrm{K}_{21}-\mathrm{PEG}_{22}$ (Figures $\mathrm{S} 4 \mathrm{a}-\mathrm{b})$, it has a sigmoidal growth, associated to a hydrophobic collapse, for $\mathrm{K}_{17}$-Eoct and $\mathrm{K}_{21}$-Eoct (Figures $\mathrm{S} 4 \mathrm{c}-\mathrm{d}$ ). As discussed in the paragraph above, $\mathrm{K}_{17}$-Eoct and $\mathrm{K}_{21^{-}}$ Eoct also show the highest $I / I_{o}$ ratios.

Figure 2 shows the presence of a cac $0.03 \mathrm{wt} \%$ for $\mathrm{K}_{17}$-Eoct and $\mathrm{K}_{21}$-Eoct, as determined from the $I / I_{o}$ vs $\log (c)$ plots. The hydrophobic collapse of $\mathrm{K}_{17}$-Eoct and $\mathrm{K}_{21^{-}}$ Eoct indicates the self-assembly of nanostructures different from $\mathrm{PYY}_{3-36}$ fibres, as will be discussed later in the manuscript.

$\mathrm{CD}$ was used to study changes in the secondary structure of $\mathrm{K}_{17}$-Eoct, $\mathrm{K}_{21}$-Eoct, $\mathrm{K}_{17-}$ $\mathrm{PEG}_{22}$ and $\mathrm{K}_{21}-\mathrm{PEG}_{22}$ as a function of concentration, in the range $4.3 \times 10^{-2} \mathrm{wt} \%-0.08$ wt $\%$ conjugated peptide. The spectra in Figure 3 show the characteristics of an $\alpha$-helical secondary structure. ${ }^{50}$ The CD spectra in Figure 3 were used to calculate $f_{\alpha}$ and $[\theta]_{222} /[\theta]_{208}$. The results are displayed in Figure 4 as a function of the sample concentration, which shows that $f_{\alpha}$ decreases substantially with concentration for $\mathrm{K}_{17-}$ Eoct and $\mathrm{K}_{21}$-Eoct and $\mathrm{K}_{17}-\mathrm{PEG}_{22}$ (Figure 4a, c-d). This situation is reversed for $\mathrm{K}_{21^{-}}$ $\mathrm{PEG}_{22}$, which reaches higher and stable values of $f_{\alpha}$ at higher concentration (Figure $4 \mathrm{~b}$ ). The explanation for this is not completely clear, but it may to be due to the increased presence of small aggregates (dimers and tetramers) revealed uniquely for this sample by AUC (to be discussed shortly). As a whole, $f_{\alpha}$ values are at least two times higher in Figure 4 than in Figure 1d. Thus, PEGylation or lipidation of PYY $\mathrm{P}_{3-36}$ unexpectedly promotes $\alpha$-helical formation.

As mentioned above, values $[\theta]_{222} /[\theta]_{208} \sim 1$ or higher indicate the formation of coiled coil aggregates of $\alpha$-helices whereas significantly lower values are characteristic of single stranded $\alpha$-helices. ${ }^{34,49-52}$ 
Measured values for $[\theta]_{222} /[\theta]_{208}$ show that none of the PEGylated conjugates form coiled coil structures. In fact, the maximum value $[\theta]_{222} /[\theta]_{208} \sim 0.87$, for $\mathrm{K}_{21}-\mathrm{PEG}_{22}$ corresponds to single $\alpha$-helical helices (Figure 4b).

For $\mathrm{K}_{17}$-Eoct and $\mathrm{K}_{21}$-Eoct $[\theta]_{222} /[\theta]_{208}$ changes from $1.05-1.01$ to $0.82-0.78$ with increasing concentration and the decrease occurs at the $c a c$ (Figures $4 c-d)$. As for the PEGylated peptides, Figures $4 \mathrm{c}-\mathrm{d}$ suggest the presence of mostly single $\alpha$-helixcontaining peptide structures, even above the $c a c$, for the lipidated peptides. This is in good agreement with the tendency for aggregate formation through hydrophobic collapse, as described shown by the ANS results discussed above.

The temperature dependence of conformation was studied using CD spectroscopy for the lipidated and PEGylated derivatives. Figure 5a displays representative results obtained for the dependence of the CD signal on the temperature measured for 0.08 wt $\% \mathrm{~K}_{21}-\mathrm{PEG}_{22}$. The dependence of the $\mathrm{CD}$ spectra with temperature for $\mathrm{K}_{17}$-Eoct, $\mathrm{K}_{21^{-}}$ Eoct and $\mathrm{K}_{17}-\mathrm{PEG}_{22}$ (Figure S5), was used together with the data in Figure 5a to calculate $f_{\alpha}$ values plotted in Figure 5 b. Increasing the temperature from $20{ }^{\circ} \mathrm{C}$ to $80{ }^{\circ} \mathrm{C}$ causes a great loss of $\alpha$-helix content for all the peptides, but refolding of the $\alpha$-helix is observed when the temperature is reduced from $80^{\circ} \mathrm{C}$ to $20^{\circ} \mathrm{C}$, i.e. the temperatureinduced conformational change is thermo-reversible (Figure 5c).

The observation that $f_{\alpha}$ decreases markedly with temperature for all four peptide conjugates, including the two PEGylated peptides is consistent with previous work that showed that attachment of PEG chains to short model $\alpha$-helical peptides does not stabilize them against reduction in coiled coil content as temperature is increased. ${ }^{25} \mathrm{~A}$ dramatic decrease of helical content with increasing temperature was also recorded by CD for palmitoyl- conjugated $\mathrm{PYY}_{3-36}$ aqueous solutions. ${ }^{10}$ 
Analytical ultracentrifugation experiments were performed at $0.01,0.05$ and $0.1 \mathrm{wt} \%$ peptide conjugate to complement the $\mathrm{CD}$ and fluorescence probe measurements. Table S1 contains the estimated molecular weights from the $c(s)$ analysis. Figures $6 a-f$ present the sedimentation coefficient distributions obtained for these samples from the absorbance (Figures 6a,c) or interference (Figures 6b,d-f) measurement.

The molecular weight $\mathrm{M}_{\mathrm{w}}$ of the conjugated peptides listed in Table S1 is calculated through the $c(s)$ analysis and therefore depends on the frictional ratio parameter $\left(f / f_{0}\right)$. The frictional ratio is fit globally during the analysis. Therefore, if there is more than one species present, the calculated $f / f_{0}$ is an average value for all the species. Consequently, $\mathrm{M}_{\mathrm{w}}$ calculated using an average $f / f_{0}$ (Table $\mathrm{S} 1$ ) corresponds to a molecular weight averaged over all the species in the system.

The results for $\mathrm{K}_{17}-\mathrm{PEG}_{22}$ and $\mathrm{K}_{21}-\mathrm{PEG}_{22}$ are very similar (Figures 6a-d, Table S1). Results present evidence of non-ideality, probably caused by unusual molecular shapes. This manifests as a concentration dependent effect whereby the sedimentation coefficient and molecular weight of a species both get smaller with increasing sample concentration.

Solutions of $\mathrm{K}_{17}-\mathrm{PEG} 22$ and $\mathrm{K}_{21}-\mathrm{PEG}_{22}$ are dominated by species with a molecular weight consistent with that of a monomer in 0.01-0.1 wt\% solutions of PEGylated conjugate (peak 1, Figure 6a-d and Table S1). The AUC data for $\mathrm{K}_{17}-\mathrm{PEG}_{22}$ also indicates a likely equilibrium involving a population of dimeric and tetrameric coiled coils as well as monomer in 0.01-0.1 wt\% solutions (peak 2, Figure 6a-d and Table S1). The $\mathrm{K}_{21}-\mathrm{PEG}_{22}$ samples contain a significant population of species that are most likely dimers and tetramers (peaks 2 and 3, Figure 6a-d and Table S1). The relative proportion of these is given in Table $\mathrm{S} 1$. The $\mathrm{K}_{21}-\mathrm{PEG}_{22}$ sample also contains a small proportion of some lower molecular weight species that could result from sample degradation. 
The results for $\mathrm{K}_{17}$-Eoct and $\mathrm{K}_{21}$-Eoct are very similar (Figure 6e-f, Table S1). Both appear as predominantly a single non-ideal species (peak 1). Given the apparent molecular weight, the predominant species for $\mathrm{K}_{17}$-Eoct and $\mathrm{K}_{21}$-Eoct is likely to be monomer for the solutions with $0.01-0.1 \mathrm{wt} \%$ lipidated peptide. There is also evidence of a small amount of larger species in both samples at 0.05 and $0.1 \mathrm{wt} \% \mathrm{~K}_{17}$-Eoct and 0.01-0.1 wt $\% \mathrm{~K}_{21}$-Eoct (peak 2, Figure 6e-f, Table S1). This is likely to indicate the presence of aggregates since the $c a c$ is estimated to be $0.03 \mathrm{wt} \%$ according to ANS fluorescence probe studies (Figure 2) The molecular weights listed for peak 2 (K $\mathrm{K}_{17}$-Eoct and $\mathrm{K}_{21}$-Eoct samples, Table $\mathrm{S} 1$ ) indicate that the apparent association number ( $\mathrm{p}$ ) of these oligomeric clusters is in the range 5-10. This result actually agrees with the value $(\mathrm{p}=7)$ estimated for micelles made of $\mathrm{PYY}_{3-36}$ lipidated at positions 11 or 23 with a palmitoyl chain at $\mathrm{pH} 2$ and 4 reported by us in a previous study of $\mathrm{PYY}_{3-36}$ conjugates. $^{10}$

The self-assembly of the peptide conjugates in solution was investigated using SAXS at $0.5 \mathrm{wt} \%$ peptide conjugate. The corresponding SAXS curves are displayed in Figure 7. The shape of the SAXS curves for the PEGylated peptides is different from the shape of the SAXS curves for the lipidated peptides. The SAXS data for $\mathrm{K}_{17}-\mathrm{PEG}_{22}$ and $\mathrm{K}_{21}$ $\mathrm{PEG}_{22}$ (Figure 7a) was fitted using the form factor of a Gaussian coil, while the SAXS data for $\mathrm{K}_{17}$-Eoct and $\mathrm{K}_{21}$-Eoct (Figure $7 \mathrm{~b}$ ) was fitted using a spherical core and shell form factor, consistent with the presence of spherical micelles. These models provide excellent representations of the SAXS intensity profiles. The parameters obtained from the SAXS fittings are listed in Table S2.

The fitting of the SAXS data for PEGylated peptides describes the structure of a solution rich in oligomeric species (Figure 7a). The radius of gyration of PEG with a molar mass of $22,000 \mathrm{~g} \mathrm{~mol}^{-1}$ is estimated to be $R_{\mathrm{g}}=51 \AA$, which is close to $R_{\mathrm{g}}=50 \AA$ 
obtained from the fitting of the SAXS data for $0.5 \mathrm{wt} \% \mathrm{~K}_{21}-\mathrm{PEG}_{22}$ in Figure $7 \mathrm{a}$ (Table S2). Therefore, SAXS indicates the existence of monomers or small oligomers in 0.5 and $1 \mathrm{wt} \%$ solutions of $\mathrm{K}_{21}-\mathrm{PEG}_{22}$ (SAXS data not shown for $1 \mathrm{wt} \%$ sample). On the other hand, $R_{\mathrm{g}}=130 \AA$ obtained for $0.5 \mathrm{wt} \% \mathrm{~K}_{17}-\mathrm{PEG}_{22}$ (Table S2) suggests the formation of oligomers in solution. The excluded volume parameter $\mu=0.4$ and 0.57 for $\mathrm{K}_{17}-\mathrm{PEG}_{22}$ and $\mathrm{K}_{21}-\mathrm{PEG}_{22}$ respectively shows that the PEG chain is more swollen for the $\mathrm{K}_{17}-\mathrm{PEG}_{22}$ oligomer than for the $\mathrm{K}_{21}-\mathrm{PEG}_{22}$ monomer.

The fitting of the SAXS data for lipidated peptides indicates the formation of micelles with a well-defined core- shell structure. According to this model, $\mathrm{K}_{17}$-Eoct and $\mathrm{K}_{21^{-}}$ Eoct micelles have an external polydisperse radius $R_{1}=(20 \pm 5.5) \AA$ and $(19.5 \pm 5.5) \AA$ respectively (Table S2). The internal micellar core radius is $\mathrm{R}_{2}=7 \AA$ and $9.2 \AA$ for $\mathrm{K}_{17-}$ Eoct and $\mathrm{K}_{21}$-Eoct respectively (Table $\mathrm{S} 2$ ).

Based on the analysis of CD, AUC and SAXS data, at low concentration PEGylated conjugates are present as populations of dimeric and tetrameric coiled coil structures, along with a large population of monomers. In contrast, lipidated peptides form micelles for concentrations equal or higher than $0.5 \mathrm{wt} \%$.

Cryo-TEM experiments were carried out on samples containing $2 \mathrm{wt} \%$ conjugated peptides, in order to obtain images of the self-assembled nanostructure. We did not observe discrete nanostructures in any cryo-TEM images for the PEGylated peptides. This is consistent with the presence of monomers and only small oligomers. In contrast, cryo-TEM images for the lipidated peptides show the formation of micelles $\sim 35-45 \AA$ in diameter (Figure 8a-b). Along with the molecular volume, estimated to be $4901 \AA^{3}$ for $\mathrm{PYY}_{3-36}$, estimated based on residue specific partial volumes ${ }^{60}$ (which will not be significantly modified by attachment of one side octyl chain) and the estimate micelle radius estimated from SAXS (20 $)$ ), the association number of the lipidated peptide 
aggregates is found to be approximately $p=7$. This corresponds to small oligomeric structures and differs from the typical association numbers (several tens or even hundreds) for surfactant micelles. ${ }^{61-62}$ This value is in good agreement with AUC results which indicate the formation of small oligomers containing 5-10 molecules for the two lipidated peptides (Table S1) and with a previous report on micelles formed by palmitoylated $\mathrm{PYY}_{3-36}$ derivatives. ${ }^{10}$

In summary, cryo-TEM results are in good agreement with AUC and SAXS results discussed above indicating the absence of large aggregate structures for $\mathrm{K}_{17}-\mathrm{PEG}_{22}$ and $\mathrm{K}_{21}-\mathrm{PEG}_{22}$ and the self-assembly of spherical micelles $\sim 40 \AA$ in diameter for $\mathrm{K}_{17}$-Eoct and $\mathrm{K}_{21}$-Eoct.

\section{Conclusions}

We have compared the conformation and self-assembly behaviours of lipidated and

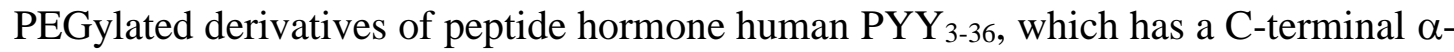
helical domain. The influence of solution concentration on the conformation and selfassembly has been examined. The effect of lipidation and PEGylation in stabilizing $\alpha$ helical conformation against changes in temperature has been probed.

CD spectra confirm the presence of $\alpha$-helical content for $\mathrm{PYY}_{3-36}$ at low concentration, with a significant degree of coiled coil formation at low concentration. However at sufficiently high concentration (above the cac determined through ThT fluorescence measurements) cryo-TEM reveals fibril structures with an $\alpha$-helical secondary structure. The peptide is not stable against heating and the $\alpha$-helical conformation is lost upon heating to $80{ }^{\circ} \mathrm{C}$ in a "denaturing process". However, this is fully reversible as shown by the recovery of the $\mathrm{CD}$ spectrum at $20^{\circ} \mathrm{C}$. The formation of fibrils by $\alpha-$ 
helical PYY $3-36$ is noteworthy. Although these may not be typical amyloid fibrils (since Congo red binding is not observed), it may be noted that several classes of peptide hormone form amyloid structures which are useful storage depots, ${ }^{63-64}$ regulating their activity in vivo. Whether $\mathrm{PYY}_{3-36}$ forms "amyloid" (or at least fibril structures) under physiological conditions is a subject for future investigation, however it may be noted that it was observed to form amyloid in acidic aqueous conditions (without physiological buffers). ${ }^{10}$ Potential concentration-dependent self-assembly of lipidated and PEGylated PYY 3-36 derivatives was assayed via ANS fluorescence measurements. This indicated that the two lipidated derivatives show a critical aggregation concentration whereas the two PEGylated peptides do not show aggregation behaviour. CD spectra indicate that surprisingly both lipidated and PEGylated conjugates have significantly higher $\alpha$-helix content than the native PYY $\mathrm{PY}_{36}$ peptide. In addition, CD shows that the PEGylated peptides form monomers and only small oligomers, which is consistent with the PEG forming a steric barrier around isolated peptides, thus preventing their association. SAXS also shows that solutions of the PEGylated peptides are dominated by monomers and oligomeric structures, with a radius of gyration comparable to that of 22,000 $\mathrm{g} \mathrm{mol}^{-1} \mathrm{PEG}$ chains. However, AUC indicates the presence of a fraction of, especially, dimeric aggregates, in particular for $\mathrm{K}_{21}-\mathrm{PEG}_{22}$. This conjugate shows a unique concentration-dependent increase in $\alpha$-helical content, in contrast to all other peptides studied. This highlights the importance of the site of PEGylation. PEGylation at residue 21 corresponds to loss of the negative charge of the lysine residue in the native peptide sequence whereas PEGylation at residue 17 corresponds to replacement of hydrophobic leucine with the PEGylated residue (leading to enhanced peptide solubility). The CD spectra show that PEGylation (at either position 17 or 21) enhances the thermal stability of the peptide, because there is 
a much reduced change in $\alpha$-helix conformation with temperature compared to the native peptide (and also reduced concentration dependence).

The behaviour of the two lipidated peptides is quite distinct from that of the two PEGylated derivatives, or that of PYY $\mathrm{PY}_{36}$ itself. Fluorescence assays using ANS show a critical aggregation process associated with hydrophobic collapse. The cac is also evident in plots of the concentration-dependent $\alpha$-helix content obtained from CD spectra (or coiled coil content which tracks $\alpha$-helix content). Cryo-TEM shows the presence of well-defined micelles with a diameter of $4 \mathrm{~nm}$. AUC also indicates a population of aggregate structures with a low degree of association. This is consistent with the estimated aggregation number $(p=7)$ from the observed micelle volume divided by molecular volume. These structures are oligomeric species rather than conventional surfactant-like micelles which typically have a much larger association number. ${ }^{61-62}$ The small size of the alkyl chains relative to the hydrophilic peptide "head groups" does not permit close packing in micelles with a large association number which are observed for conventional amphiphiles where the hydrophilic moiety is much smaller (smaller than the lipid chain or comparable to it). CD shows that lipidation does not improve thermal stability of $\alpha$-helix conformation to the same extent as PEGylation. Our results show that PEGylation and lipidation are potentially valuable strategies to tune the conformation of peptide hormones, in particular to enhance their thermostability. PEGylation reduces coiled coil aggregation whereas lipidation leads to the formation of small oligomeric structures above a critical aggregation concentration. These findings may benefit the development of future therapeutics based on $\mathrm{PYY}_{3-36}$ 
Acknowledgements. This work was supported by EPSRC Platform Grant “Nanostructured Polymeric Materials for Healthcare" (EP/L020599/1). We are grateful to the ESRF for beamtime on ID02 (ref. SC4739) and Alessandro Mariani for support during the beamtime. We thank Diamond for beamtime on B21 (refs. sm14684-1 and sm17118-1) and Katsuaki Inoue and Nathan Cowieson for support during the SAXS experiments.

\section{Supporting Information}

The Supporting Information is available free of charge on the ACS Publications website at DOI: XX.XXXX/acs.langmuir.XXXXXXX

SAXS models used in this work, parameters obtained from the AUC analysis and the SAXS fittings, fluorescence and CD results. 
Figures and Schemes

(a)

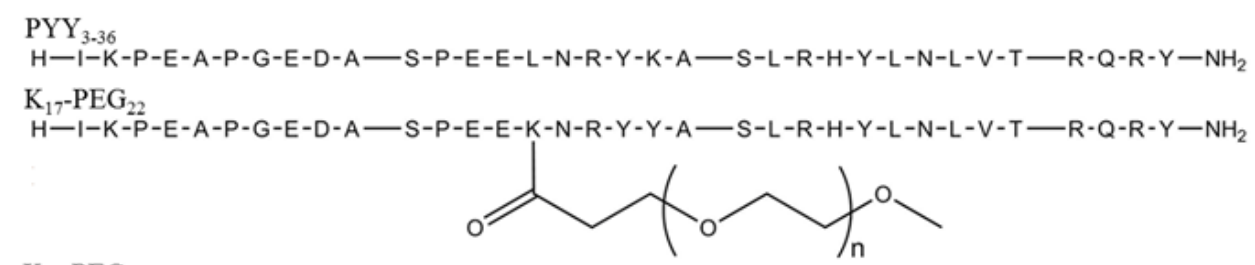

$\mathrm{K}_{21}-\mathrm{PEG}_{22}$

H-I-K-P-E-A-P-G-E-D-A-S-P-E-E-L-N-R-Y-K-A-S-L-R-H-Y-L-N-L-V-T-R-Q-R-Y-NH<smiles>COCCOC(C)(C)CC(N)=O</smiles>

$\mathrm{K}_{17}$-Eoct

H-I-K-P-E-A-P-G-E-D-A -S-P-E-E-K-N-R-Y-Y-A CS-L-R-H-Y-L-N-L-V-T—R-Q-R-Y-NH

$\mathrm{K}_{21}$-Eoct<smiles>CCCCCCCC(C)=O</smiles>

H-I-K-P-E-A-P-G-E-D-A - S-P-E-E-L-N-R-Y-K-A -S-L-R-H-Y-L-N-L-V-T-R-Q-R-Y-NH<smiles>CCCCCCCC(C)=O</smiles>

(b)

IKPEAPGEDASPEELNRYYASLRHYLNLVTRQRY (c)

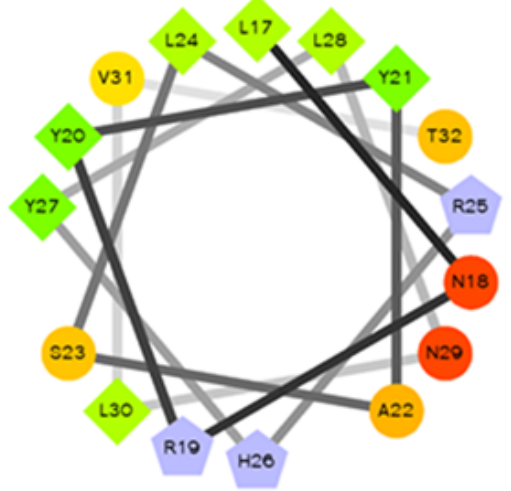

Scheme 1. (a) Molecular Structures of the derivatives studied. Residues L(17) or Y(21) are substituted with lysine derivatives with octyl lipid chains or short PEG chains attached via $\gamma$-glutamic acid linkers. (b) $\mathrm{PYY}_{3-36}$ with residues in the $\alpha$-helical domain, determined by solution NMR studies, ${ }^{7,8}$ highlighted in red. (c) Helical wheel representation of $\mathrm{PYY}_{3-36}$ (generated using http://rzlab.ucr.edm /scripts/wheel/wheel.cgi,). The hydrophilic residues are represented as circles, hydrophobic residues as diamonds, and potentially positively charged as pentagons. Hydrophobicity is colour coded: the most hydrophobic residue is green, and the amount of green decreases proportionally to the hydrophobicity, with zero hydrophobicity coded as yellow. The potentially charged residues are light blue. Hydrophilic residues are coded red with pure red being the most hydrophilic (uncharged) residue, and the amount of red decreasing proportionally to the hydrophilicity. The boxes indicate sites of lipidation or PEGylation with the residues indicated replaced as shown in (a). 
(a)

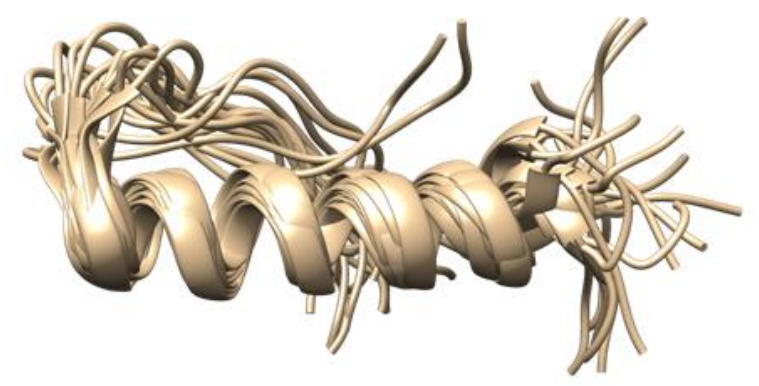

(b)

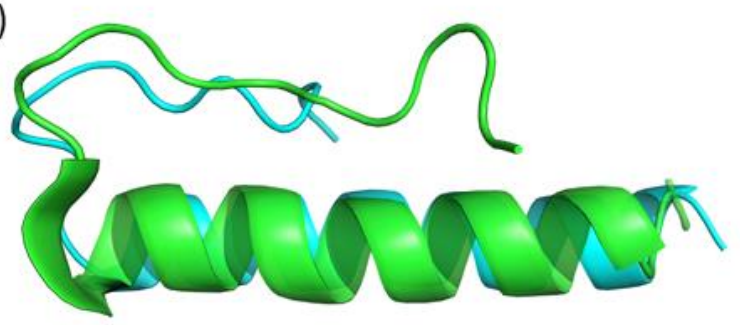

(c)

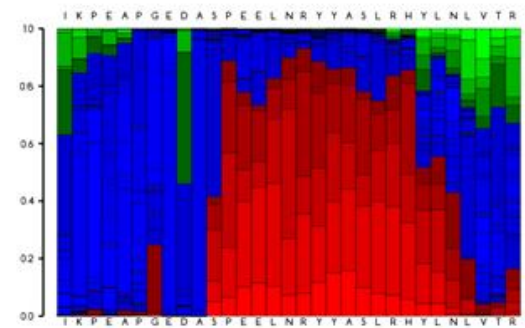

Scheme 2. (a) Ensemble of conformations from solution NMR (pdb file: 2dez) of human PYY(3-36). ${ }^{12}$ (b) Overlay of experimental (green) and PEPfold3 predicted (cyan) structures (in each case the first model from the ensemble is taken for convenience). (c) The predicted local structure analysis. Red is helical, blue is coil (disordered) and green is 'extended'. Obtained using PEPfold3. ${ }^{39-40}$ 

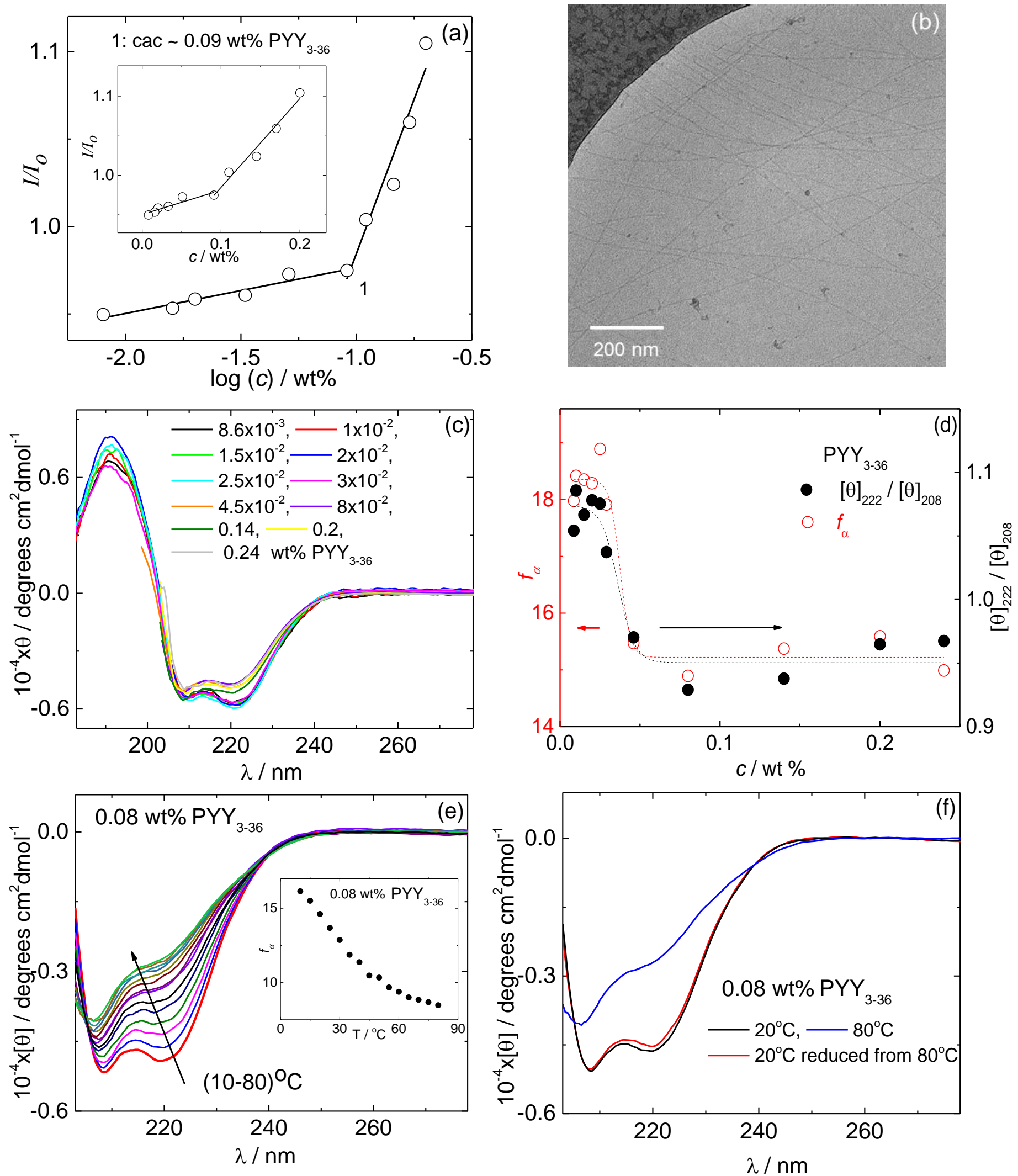

Figure 1. PYY 3 -36 in solution: (a) ThT fluorescence assay; (b) cryo-TEM image; (c) concentration dependence of the $\mathrm{CD}$ signal; (d) $f_{\alpha}$ and $[\theta]_{222} /[\theta]_{208}$ calculated from (c); 
(e) temperature dependence of the CD signal (inset displays calculated $f_{\alpha}$ ) and (f) thermal reversibility of the $\mathrm{PYY}_{3-36}$ helix unfolding, probed by $\mathrm{CD}$.
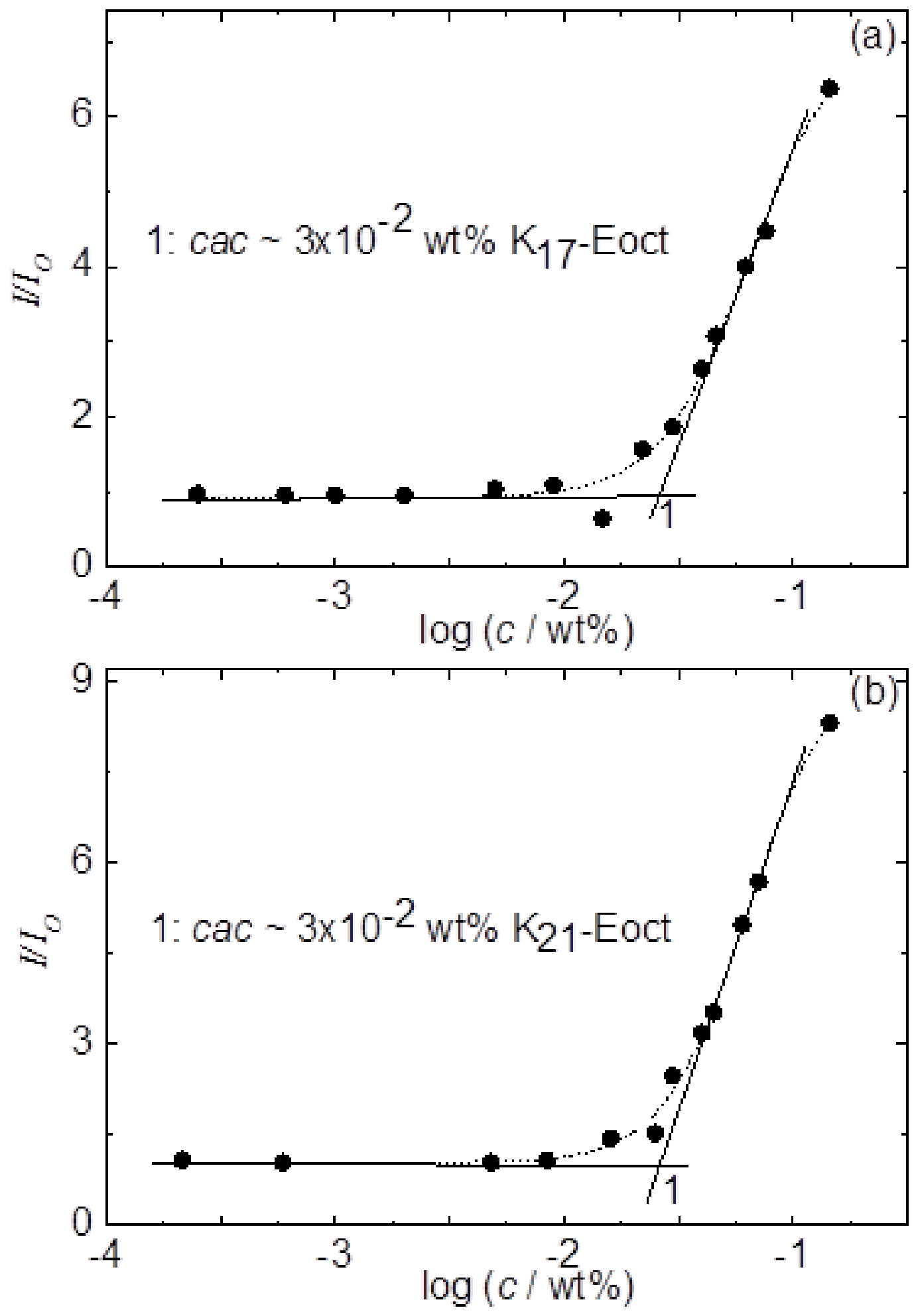
Figure 2. Fluorescence intensity $(I)$ normalized to that of ANS in aqueous solution $\left(I_{0}\right)$ at the emission wavelength $\lambda_{\mathrm{em}}$, plotted as a function of the lipidated peptide concentration $c$ : (a) $\mathrm{K}_{17}$-Eoct, (b) $\mathrm{K}_{21}$-Eoct.
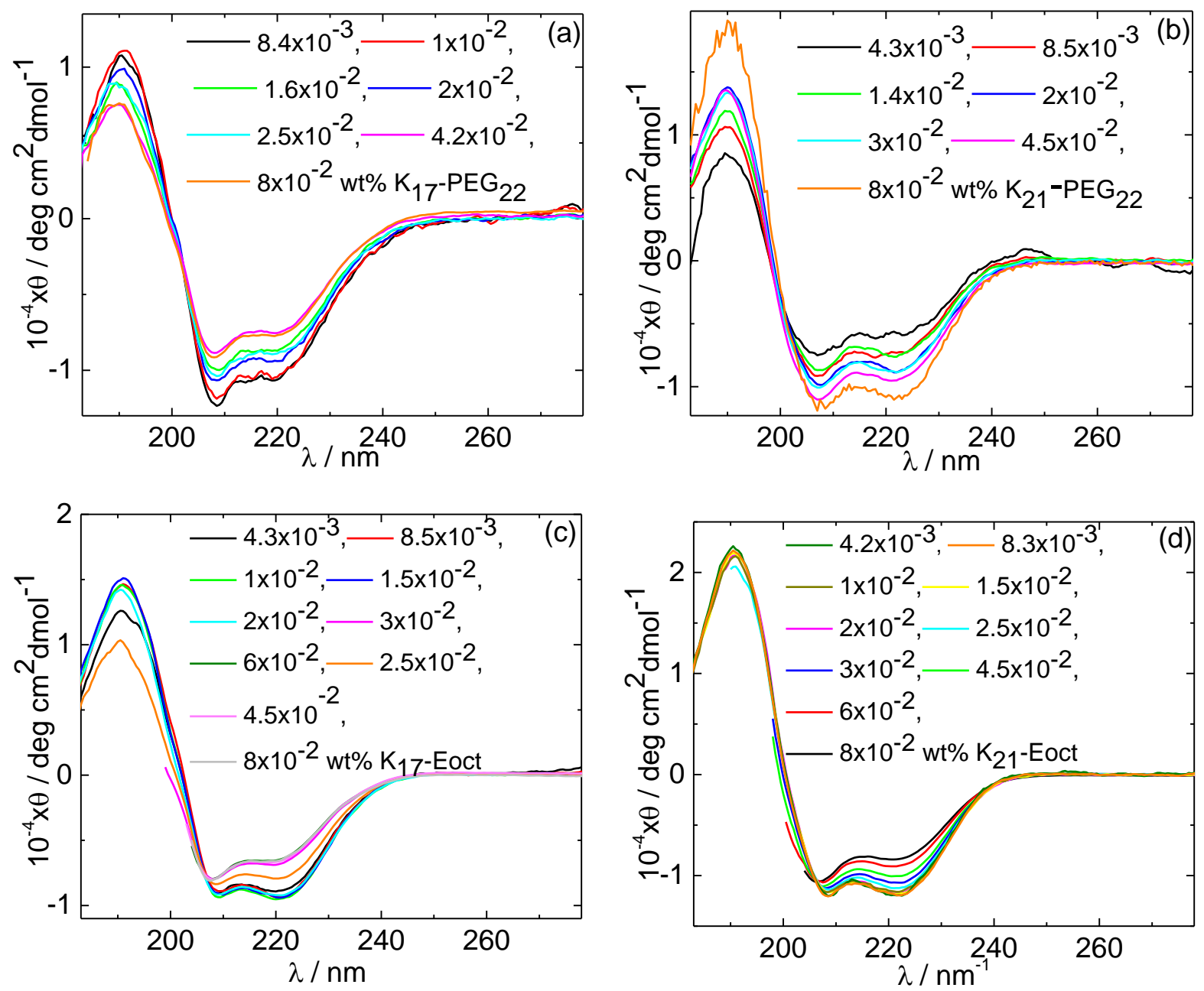

Figure 3. Concentration-dependent circular dichroism spectra (a) $\mathrm{K}_{17}-\mathrm{PEG}_{22}$, (b) $\mathrm{K}_{21}$ $\mathrm{PEG}_{22}$, (c) $\mathrm{K}_{17}$-EOct and (d) $\mathrm{K}_{21}$-EOct. 

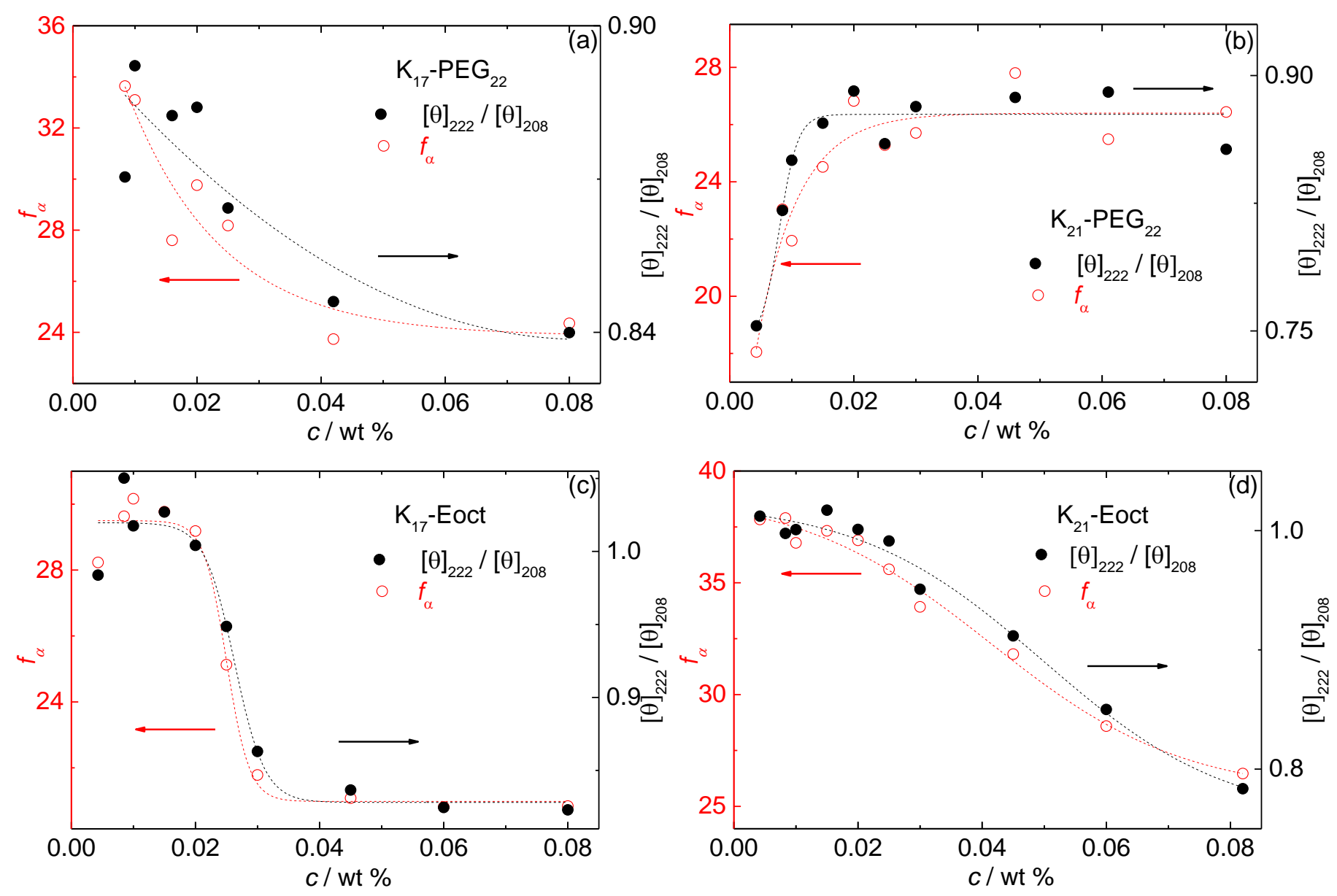

Figure 4. Concentration-dependent conformational analysis of circular dichroism spectra $-f_{\alpha}$ denotes helix content and the ratio $[\theta]_{222} /[\theta]_{208}$ is a measure of coiled coil content, both calculated from the data plotted in Figure 3. (a) $\mathrm{K}_{17}-\mathrm{PEG}_{22}$, (b) $\mathrm{K}_{21^{-}}$ $\mathrm{PEG}_{22}$, (c) $\mathrm{K}_{17-E O c t}$ and (d) $\mathrm{K}_{21}$-EOct. 

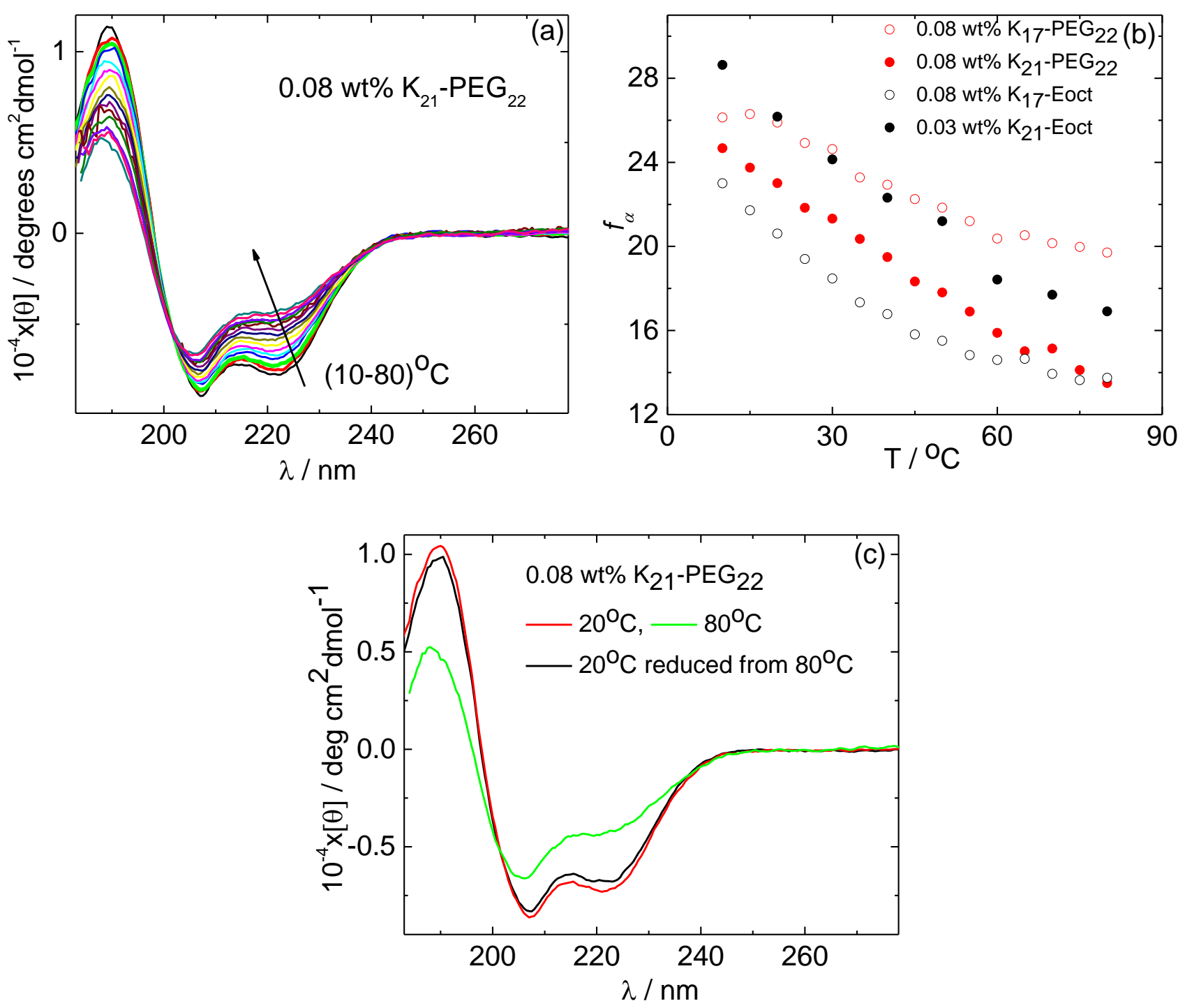

Figure 5. (a) Temperature-dependent $\mathrm{CD}$ spectra for $0.08 \mathrm{wt} \% \mathrm{~K}_{21}-\mathrm{PEG}_{22}$, (b) dependence of $f_{\alpha}$ on the temperature, calculated from the CD spectra for all the peptide conjugates, (c) Showing thermoreversibility of CD spectra for $\mathrm{K}_{21}-\mathrm{PEG}_{22}$. 

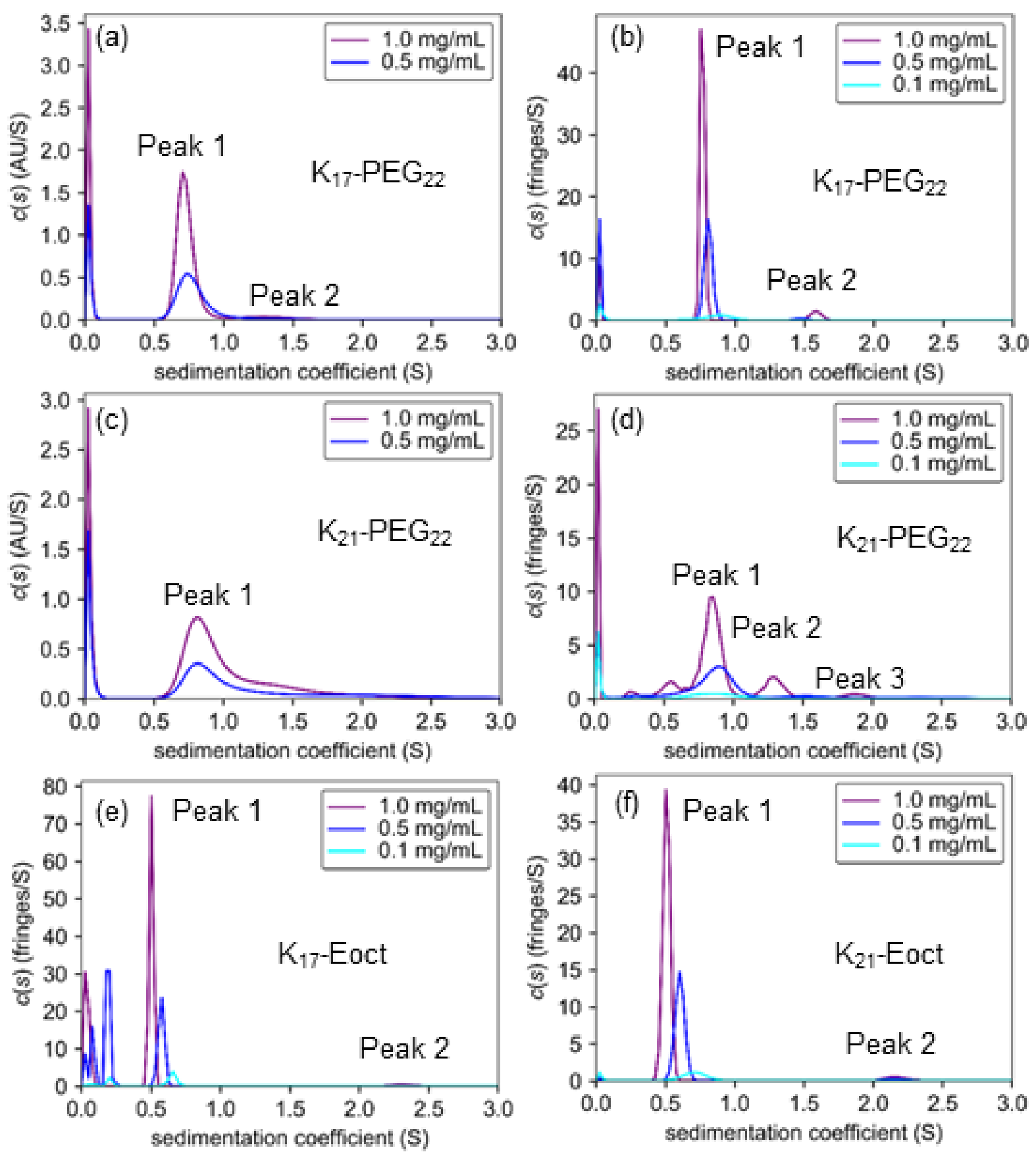

Figure 6. Sedimentation coefficient distributions. (a,c) Absorbance data. (b,d-f) Interference data. 

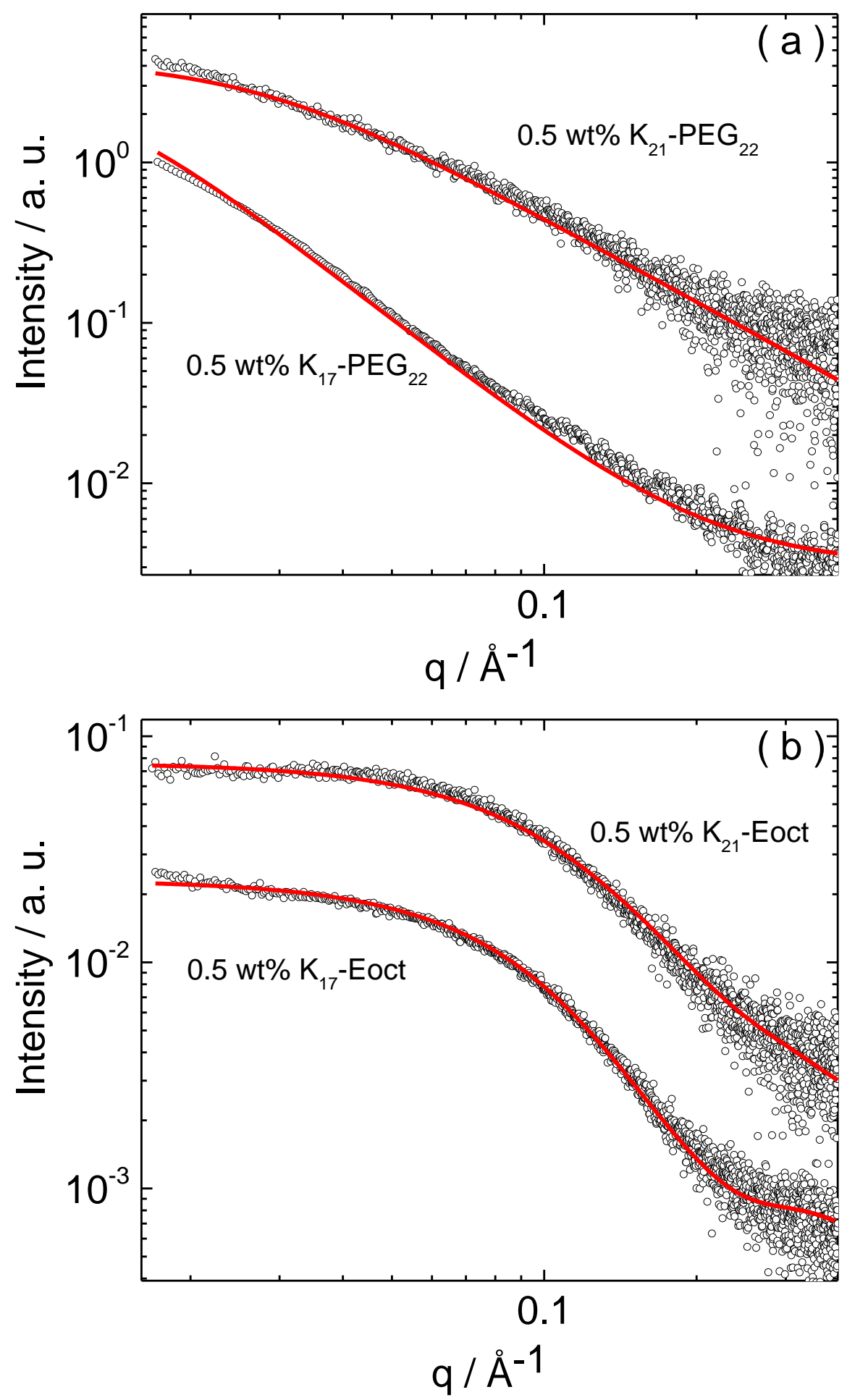

Figure 7. SAXS data measured for $0.5 \mathrm{wt} \%$ of (a) $\mathrm{K}_{17}-\mathrm{PEG}_{22}$ and $\mathrm{K}_{21}-\mathrm{PEG}_{22}$ and (b) $\mathrm{K}_{17}$-Eoct and $\mathrm{K}_{21}$-Eoct. The full lines are the fitting top the data. The SAXS curves have been multiplied by an arbitrary factor in order to aid visualisation. 

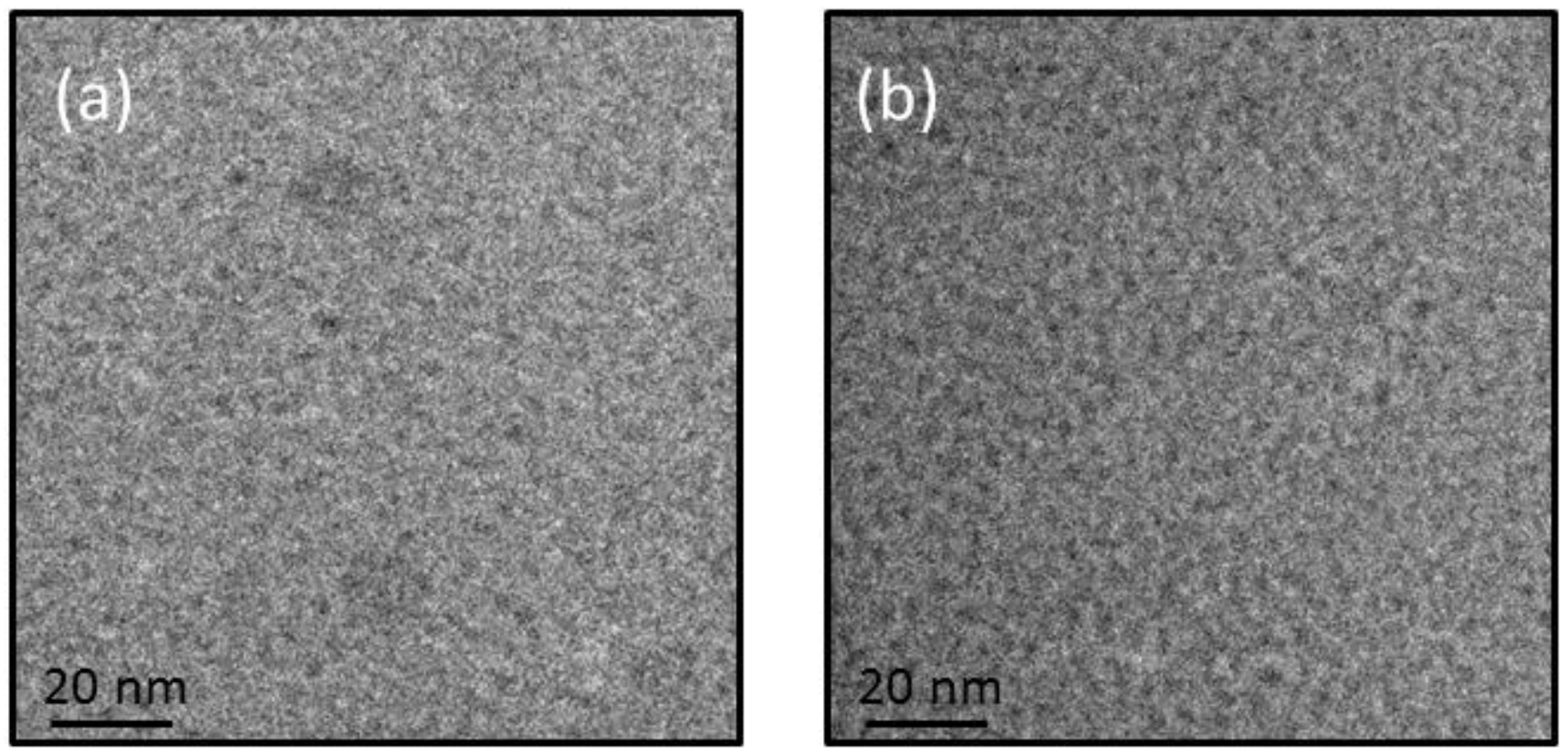

Figure 8. Cryo-TEM images for $2 \mathrm{wt} \%$ solutions of (a) $\mathrm{K}_{17}$-Eoct and (b) $\mathrm{K}_{21}$-Eoct 


\section{References}

1. Hutchinson, J. A.; Burholt, S.; Hamley, I. W., Peptide hormones and lipopeptides: from self-assembly to therapeutic applications. J. Peptide Sci. 2017, $23(2), 82-94$.

2. Huda, M. S. B.; Wilding, J. P. H.; Pinkney, J. H., Gut peptides and the regulation of appetite. Obes. Rev. 2006, 7 (2), 163-182.

3. Hazelwood, R. L., The pancreatic-polypeptide (PP-fold) family - gastrointestinal, vascular, and feeding behavioral-implications. Proc. Soc. Exp. Biol. Med. 1993, $202(1), 44-63$.

4. Moran, T. H., Pancreatic polypeptide: More than just another gut hormone? Gastroenterology 2003, 124 (5), 1542-1544.

5. Ehrlich, G. K.; Michel, H.; Truitt, T.; Riboulet, W.; Pop-Damkov, P.; Goelzer, P.; Hainzl, D.; Qureshi, F.; Lueckel, B.; Danho, W.; Conde-Knape, K.; Konkar, A., Preparation and characterization of albumin conjugates of a truncated Peptide YY analogue for half-life extension. Bioconjugate Chem. 2013, 24 (12), 2015-2024.

6. Keire, D. A.; Bowers, C. W.; Solomon, T. E.; Reeve, J. R., Structure and receptor binding of PYY analogs. Peptides 2002, 23 (2), 305-321.

7. Keire, D. A.; Mannon, P.; Kobayashi, M.; Walsh, J. H.; Solomon, T. E.; Reeve, J. R., Primary structures of PYY, Pro ${ }^{34}$ PYY, and PYY-(3-36) confer different conformations and receptor selectivity. Am. J. Physiol.-Gastroint. Liver Physiol. 2000, 279 (1), G126-G131.

8. Keire, D. A.; Kobayashi, M.; Solomon, T. E.; Reeve, J. R., Solution structure of monomeric peptide YY supports the functional significance of the PP-fold. Biochemistry 2000, 39 (32), 9935-9942. 
9. Shechter, Y.; Tsubery, H.; Mironchik, M.; Rubinstein, M.; Fridkin, M., Reversible PEGylation of peptide YY3-36 prolongs its inhibition of food intake in mice. FEBS Letters 2005, 579 (11), 2439-2444.

10. Hutchinson, J. A.; Burholt, S.; Hamley, I. W.; Lundback, A. K.; Uddin, S.; dos Santos, A. G.; Reza, M.; Seitsonen, J.; Ruokolainen, J., The effect of lipidation on the self-assembly of the gut-derived peptide hormone $\mathrm{PYY}^{3-36}$. Bioconjugate Chem. 2018, 29, 2296-2308.

11. Beck-Sickinger, A. G.; Wieland, H. A.; Wittneben, H.; Willim, K. D.; Rudolf, K.; Jung, G., Complete L-alanine scan of neuropeptide-Y reveals ligands binding to $\mathrm{Y}_{1}$ and $\mathrm{Y}_{2}$ receptors with distinguished conformations. Eur. J. Biochem. 1994, $225(3), 947-958$.

12. Nygaard, R.; Nielbo, S.; Schwartz, T. W.; Poulsen, F. M., The PP-fold solution structure of human polypeptide YY and human PYY3-36 as determined by NMR. Biochemistry 2006, 45 (27), 8350-8357.

13. Henry, K. E.; Elfers, C. T.; Burke, R. M.; Chepurny, O. G.; Holz, G. G.; Blevins, J. E.; Roth, C. L.; Doyle, R. P., Vitamin B-12 Conjugation of Peptide-YY3-36 Decreases Food Intake Compared to Native Peptide-YY3-36 Upon Subcutaneous Administration in Male Rats. Endocrinology 2015, 156 (5), 1739-1749.

14. Henry, K. E.; Kerwood, D. J.; Allis, D. G.; Workinger, J. L.; Bonaccorso, R. L.; Holz, G. G.; Roth, C. L.; Zubieta, J.; Doyle, R. P., Solution Structure and Constrained Molecular Dynamics Study of Vitamin B-12 Conjugates of the Anorectic Peptide PYY(3-36). ChemMedChem 2016, 11 (9), 1015-1021.

15. Zapadka, K. L.; Becher, F. J.; dos Santos, A. L. G.; Jackson, S. E., Factors affecting the physical stability (aggregation) of peptide therapeutics. Interface Focus 2017, 7 (6), 18. 
16. Erak, M.; Bellmann-Sickert, K.; Els-Heindl, S.; Beck-Sickinger, A. G., Peptide chemistry toolbox - Transforming natural peptides into peptide therapeutics. Bioorg. Med. Chem. 2018.

17. Delgado, C.; Francis, G. E.; Fisher, D., Crit. Rev. Therapeutic Drug Carrier Syst. 1992, $9(3,4), 249-304$.

18. Duncan, R., The dawning era of polymer therapeutics. Nature Rev. Drug Discovery 2003, 2 (5), 347-360.

19. Ryan, S. M.; Mantovani, G.; Wang, X.; Haddleton, D. M.; Brayden, D. J., Advances in PEGylation of important biotech molecules: delivery aspects. Expert Opin. Drug Deliv. 2008, 5, 371-383.

20. Knop, K.; Hoogenboom, R.; Fischer, D.; Schubert, U. S., Poly(ethylene glycol) in drug delivery: Pros and cons as well as potential alternatives. Angew. Chem. Int. Ed. Engl. 2010, 49 (36), 6288-6308.

21. Alconcel, S. N. S.; Baas, A. S.; Maynard, H. D., FDA-approved poly(ethylene glycol)-protein conjugate drugs. Polym. Chem. 2011, 2 (7), 1442-1448.

22. Hamley, I. W., PEG-Peptide Conjugates. Biomacromolecules 2014, 15 (5), 1543 1559.

23. Hamley, I. W.; Castelletto, V., Self-Assembly of peptide bioconjugates: Selected recent research highlights. Bioconjugate Chem. 2017, 28 (3), 731-739.

24. Thieme, V.; Jolly, N.; Madsen, A. N.; Bellmann-Sickert, K.; Schwartz, T. W.; Holst, B.; Cox, H. M.; Beck-Sickinger, A. G., High molecular weight PEGylation of human pancreatic polypeptide at position 22 improves stability and reduces food intake in mice. Br. J. Pharmacol. 2016, 173 (22), 3208-3221.

25. Vandermeulen, G.; Tziatzios, C.; Klok, H., Reversible self-organization of poly(ethylene glycol)-based hybrid block copolymers mediated by a de novo 
four-stranded alpha-helical coiled coil motif Macromolecules 2003, 36, 41074114

26. Klok, H. A.; Vandermeulen, G. W. M.; Nuhn, H.; Rosler, A.; Hamley, I. W.; Castelletto, V.; Xu, H.; Sheiko, S. S., Peptide mediated formation of hierarchically organized solution and solid state polymer nanostructures. Faraday Discuss. 2005, 128, 29-41.

27. Yu, Y. C.; Berndt, P.; Tirrell, M.; Fields, G. B., Self-assembling amphiphiles for construction of protein molecular architecture. J. Am. Chem. Soc. 1996, 118 (50), 12515-12520.

28. Hamley, I. W., Lipopeptides: from self-assembly to bioactivity. Chem. Comm. 2015, 51 (41), 8574-8583.

29. Bellmann-Sickert, K.; Elling, C. E.; Madsen, A. N.; Little, P. B.; Lundgren, K.; Gerlach, L. O.; Bergmann, R.; Holst, B.; Schwartz, T. W.; Beck-Sickinger, A. G., Long-acting lipidated analogue of human pancreatic polypeptide is slowly released into circulation. J. Med. Chem. 2011, 54 (8), 2658-2667.

30. Made, V.; Babilon, S.; Jolly, N.; Wanka, L.; Bellmann-Sickert, K.; Gimenez, L. E. D.; Morl, K.; Cox, H. M.; Gurevich, V. V.; Beck-Sickinger, A. G., Peptide modifications differentially alter G Protein-Coupled Receptor internalization and signaling Bias. Angew. Chem. Int. Ed. Engl. 2014, 53 (38), 10067-10071.

31. Hawe, A.; Sutter, M.; Jiskoot, W., Extrinsic fluorescent dyes as tools for protein characterization. Pharm. Res. 2008, 25 (7), 1487-1499.

32. LeVine, H., Thioflavine-T interaction with synthetic Alzheimers-disease betaamyloid peptides- detection of amyloid aggregation in solution. Protein Science 1993, 2, 404-410. 
33. LeVine, H., Quantification of $\beta$-sheet amyloid fibril structures with thioflavin T. . In Methods in Enzymology, Wetzel, R., Ed. Academic Press: San Diego, 1999; Vol. 309, pp 274-284.

34. Cohen, J. A.; Podgornik, R.; Hansen, P. L.; Parsegian, V. A., A Phenomenological one-parameter equation of state for osmotic pressures of PEG and other neutral flexible polymers in good solvents. J. Phys. Chem. B 2009, 113 (12), 3709-3714.

35. Durchschlag, H.; Zipper, P., Calculation of partial specific volumes and other volumetric properties of small molecules and polymers. J. Appl. Cryst. 1997, 30 (2), 803-807.

36. Schuck, P., Size-distribution analysis of macromolecules by sedimentation velocity ultracentrifugation and Lamm equation modeling. Biophys. J. 2000, 78 (3), 1606-1619.

37. Su, J. Y.; Hodges, R. S.; Kay, C. M., Effect of chain-length on the formation and stability of synthetic alpha-helical coiled coils. Biochemistry 1994, 33 (51), 15501-15510.

38. Van Vaerenbergh, P.; Leonardon, J.; Sztucki, M.; Boesecke, P.; Gorini, J.; Claustre, L.; Sever, F.; Morse, J.; Narayanan, T., An upgrade beamline for combined wide, small and ultra small-angle x-ray scattering at the ESRF. In Proceedings of the 12th International Conference on Synchrotron Radiation Instrumentation, Shen, Q.; Nelson, C., Eds. 2016; Vol. 1741.

39. Maupetit, J.; Derreumaux, P.; Tuffery, P., A Fast Method for Large-Scale De Novo Peptide and Miniprotein Structure Prediction. J. Comput. Chem. 2010, 31 (4), 726-738. 
40. Shen, Y. M.; Maupetit, J.; Derreumaux, P.; Tuffery, P., Improved PEP-FOLD Approach for Peptide and Miniprotein Structure Prediction. J. Chem. Theory Comput. 2014, 10 (10), 4745-4758.

41. Buchan, D. W. A.; Minneci, F.; Nugent, T. C. O.; Bryson, K.; Jones, D. T., Scalable web services for the PSIPRED Protein Analysis Workbench. Nucleic Acids Res. 2013, 41 (W1), W349-W357.

42. Jones, D. T., Protein secondary structure prediction based on position-specific scoring matrices. J. Molec. Biol. 1999, 292 (2), 195-202.

43. Castelletto, V.; Ryumin, P.; Cramer, R.; Hamley, I. W.; Taylor, M.; Allsop, D.; Reza, M.; Ruokolainen, J.; Arnold, T.; Hermida-Merino, D.; Garcia, C. I.; Leal, M. C.; Castaño, E., Self-assembly and anti-amyloid cytotoxicity activity of Amyloid beta peptide derivatives. Sci. Rep. 2017, 7, 12.

44. Castelletto, V.; Kirkham, S.; Hamley, I. W.; Kowalczyk, R.; Rabe, M.; Reza, M.; Ruokolainen, J., self-assembly of the toll-like receptor agonist macrophageactivating lipopeptide MALP-2 and of its constituent peptide Biomacromolecules 2016, 17, 631-640.

45. Hamley, I. W., Peptide fibrillization. Angew. Chem. Int. Ed. Engl. 2007, 46, $8128-8147$

46. Lazar, K. L.; Miller-Auer, H.; Getz, G. S.; Orgel, J.; Meredith, S. C., Helix-turnhelix peptides that form alpha-helical fibrils: Turn sequences drive fibril structure. Biochemistry 2005, 44 (38), 12681-12689.

47. Biancalana, M.; Koide, S., Molecular mechanism of Thioflavin-T binding to amyloid fibrils. Biochim. Biophys. Acta-Proteins and Proteomics 2010, 1804 (7), $1405-1412$. 
48. Groenning, M., Binding mode of Thioflavin $\mathrm{T}$ and other molecular probes in the context of amyloid fibrils-current status. J. Chem. Biol. 2010, 3 (1), 1-18.

49. Wu, C.; Wang, Z. X.; Lei, H. X.; Zhang, W.; Duan, Y., Dual binding modes of Congo red to amyloid protofibril surface observed in molecular dynamics simulations. J. Am. Chem. Soc. 2007, 129 (5), 1225-1232.

50. Kelly, S. M.; Jess, T. J.; Price, N. C., How to study proteins by circular dichroism Biochim. Biophys. Acta- Proteins and Proteomics 2005, 1751, 119-139.

51. Engel, M.; Williams, R. W.; Erickson, B. W., Designed coiled-coil proteins synthesis and spectroscopy of two 78-residue $\alpha$-helical dimers. Biochemistry 1991, 30 (13), 3161-3169.

52. Lau, S. Y. M.; Taneja, A. K.; Hodges, R. S., Synthesis of a model protein of defined secondary and quaternary structure - Effect of chain-length on the stabilization and formation of 2-stranded alpha-helical coiled-coils. J. Biol. Chem. 1984, 259 (21), 3253-3261.

53. Monera, O. D.; Zhou, N. E.; Kay, C. M.; Hodges, R. S., Comparison of Antiparallel and Parallel 2-Stranded Alpha-Helical Coiled-Coils - Design, Synthesis and Characterization. J. Biol. Chem. 1993, 268 (26), 19218-19227.

54. Zhu, B. Y.; Zhou, N. E.; Semchuk, P. D.; Kay, C. M.; Hodges, R. S., Design, Synthesis and Structural Characterization of Model Heterodimeric Coiled-Coil Proteins. Int. J. Pept. Protein Res. 1992, 40 (3-4), 171-179.

55. Woolfson, D. N., Building fibrous biomaterials from $\alpha$-helical and collagen-like coiled-coil peptides. Biopolymers 2010, 94 (1), 118-127.

56. Gasymov, O. K.; Glasgow, B. J., ANS fluorescence: Potential to augment the identification of the external binding sites of proteins. Biochim. Biophys. ActaProteins and Proteomics 2007, 1774 (3), 403-411. 
57. Munishkina, L. A.; Fink, A. L., Fluorescence as a method to reveal structures and membrane-interactions of amyloidogenic proteins. Biochim. Biophys. ActaBiomembranes 2007, 1768 (8), 1862-1885.

58. Poklar, N.; Lah, J.; Salobir, M.; Macek, P.; Vesnaver, G., pH and temperatureinduced molten globule-like denatured states of equinatoxin II: A study by UVmelting, DSC, far- and near-UV CD spectroscopy, and ANS fluorescence. Biochemistry 1997, 36 (47), 14345-14352.

59. Huttenhain, S. H.; Balzer, W., Solvatochromic Fluorescence of 8-(Phenylamino)1-Naphtalene-Ammoniumsulfonate (8,1 ANS) in 1,4-Dioxane Water Mixtures, Revisited. Z. Naturfors. Sect. A-J. Phys. Sci. 1993, 48 (5-6), 709-712.

60. Buehler, E.; Cao, Q. Oligo Calc: Oligonucleotide Properties Calculator (http://biotools.nubic.northwestern.edu/OligoCalc.html), 1996-2001.

61. Fennel Evans, D.; Wennerstrom, H., The colloidal domain. Where physics, chemistry and biology meet. New York, 1999.

62. Hamley, I. W., Introduction to Soft Matter. John Wiley: Chichester, 2007.

63. Maji, S. K.; Perrin, M. H.; Sawaya, M. R.; Jessberger, S.; Vadodaria, K.; Rissman, R. A.; Singru, P. S.; Nilsson, K. P. R.; Simon, R.; Schubert, D.; Eisenberg, D.; Rivier, J.; Sawchenko, P.; Vale, W.; Riek, R., Functional Amyloids As Natural Storage of Peptide Hormones in Pituitary Secretory Granules. Science 2009, 325 (5938), 328-332.

64. Anoop, A.; Ranganathan, S.; Das Dhaked, B.; Jha, N. N.; Pratihar, S.; Ghosh, S.; Sahay, S.; Kumar, S.; Das, S.; Kombrabail, M.; Agarwal, K.; Jacob, R. S.; Singru, P.; Bhaumik, P.; Padinhateeri, R.; Kumar, A.; Maji, S. K., Elucidating the role of disulfide bond on amyloid formation and fibril reversibility of 
Somatostatin-14. Relevance to its storage and secretion. J. Biol. Chem. 2014, 289 (24), 16884-16903. 
TOC Entry

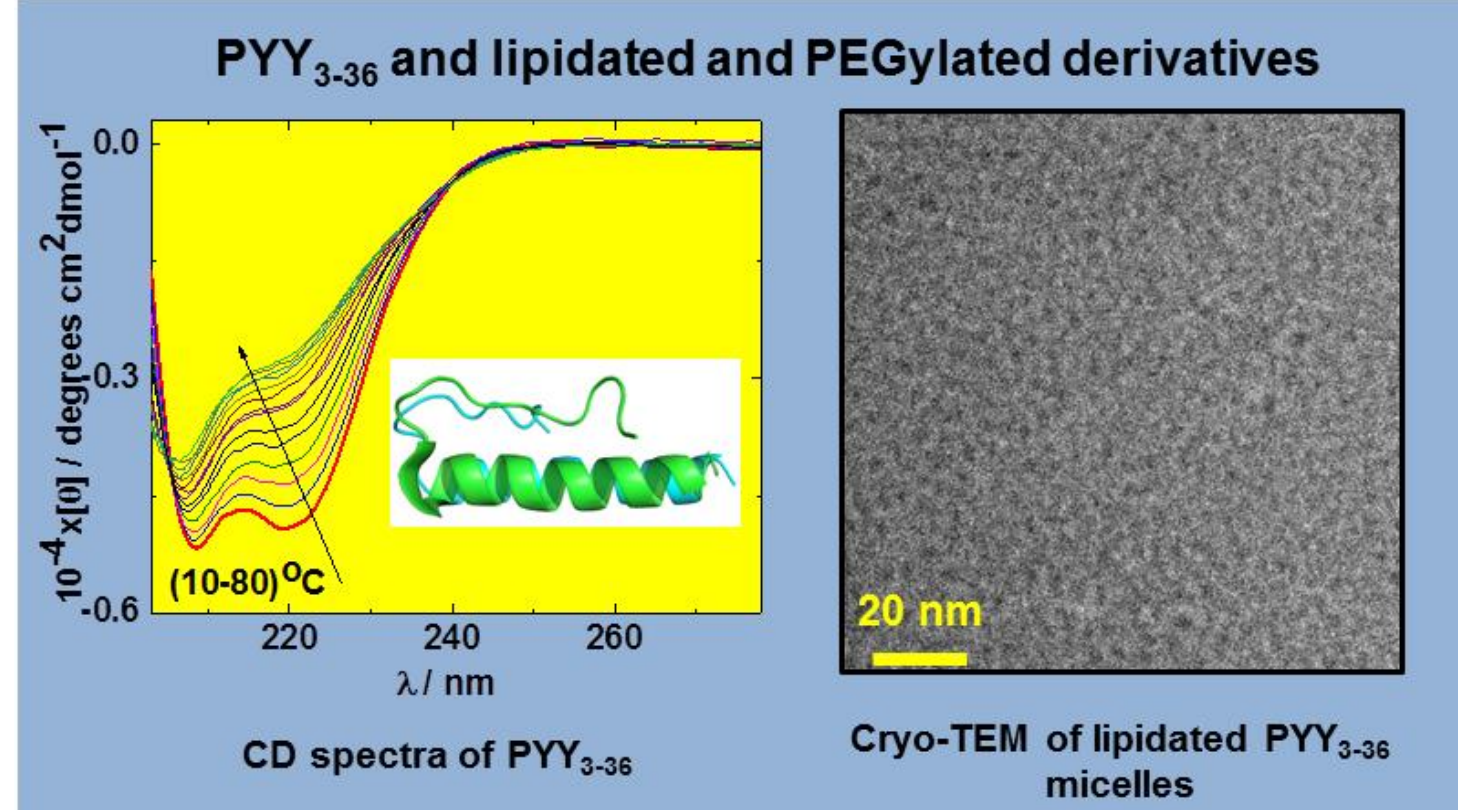

